\title{
Assessing the Impact of Modelling on the Expected Credit Loss (ECL) of a Portfolio of Small and Medium-sized Enterprises ${ }^{i}$
}

\author{
Saâd Benbachir ${ }^{1,2,3, *}$, Mohamed Habachi ${ }^{3}$ \\ ${ }^{1}$ Applied Mathematics, Management Sciences Laboratory, Morocco \\ ${ }^{2}$ The Strategic Studies in Law, Economics and Management Center, Morocco \\ ${ }^{3}$ FSJES-Agdal, Mohammed V University, Morocco
}

Copyright $\bigcirc 2018$ by authors, all rights reserved. Authors agree that this article remains permanently open access under the terms of the Creative Commons Attribution License 4.0 International License

\begin{abstract}
This paper studies the impact of the internal modelling on the calculation of expected credit loss in the framework of the international standard IFRS 9. Indeed, the probability of default of counterparty depends on the model used for the conception of the internal rating system. The multitude of probabilistic models renders uncertain and imprecise, the calculation of the expected loss for the same $S M E S$ portfolio of a Moroccan bank, as well as the comparison of losses over time due to the non-permanence of the rating system used. As a result, the regulator will be unable to guarantee an equitable and transparent system of provisioning of the losses, because of the absence of standardization of the elaboration process of the rating tool.To show this risk associated with the multitude of models, this paper studied the impact of choice of the model on the expected credit loss, by calculating of the probability of default for several types of modelling based respectively on the pure logistic regression and the logistic regression on the principal components.
\end{abstract}

Keywords Logistic Regression Model, Principal Components Analysis ( $P C A)$, Probability of Default $(P D)$, $I R B$ Foundation Approach, Excepted Loss $(E L)$

\section{Introduction}

The banking regulation defines several approaches for calculating the capital required to cover the credit risk. This enriches the techniques available for determining the risk profile of banks.

These approaches are composed of simple approaches based on the application of a coefficient, on the credit exposure and of complex approaches based on the internal rating models (Internal Ratings-Basesd IRB).
The expected loss calculation is based on the probability of default of the corporate, the loss at the time of default and the exposure, in term of outstanding amount of credit, in the event of default. Indeed, various studies were conducted to define an approach for predicting the probability of default. These studies concern linear discriminant analysis, the intelligence techniques, Bayesian networks and probabilistic models, which we will summarize as follows:

\section{- Multidimensional Linear Discriminant Analysis}

The prediction of default by linear discriminant analysis was developed by Altman [2], by defining a linear relationship between default and financial ratios. Indeed, Altman has defined a score function $(Z)$ that distinguishes between the healthy and the failing companies. The Altman's approach has been adopted by other research to determine ratios that predict failure such as those conducted by: Taffler [40], Bardos and al. [10] and Grover and Lauvin and al. [26].

\section{- Intelligence Techniques}

These techniques are based on different logics such as neural networks and genetic algorithms. The several studies have applied these techniques to predict the default of the corporates, such as those conducted by: Bel and al. [13], Back and al. [8], Liang and wu [32], Bose and Pal [16] and Oreski and al. [35].

\section{- Bayesian Network}

The Bayesian classifier (Friedman and al.,[23]) is based on the calculation of a posterior probability of each observation belonging to a specific class. Indeed, he finds the posterior probability distribution $P(Y \mid X)$, where $Y=\left(Y_{1}, \ldots Y_{n}\right)$ is a random variable to be classified in $\mathrm{k}$ categories and $X=\left(X_{1}, \ldots X_{n}\right)$ is a set of $n$ explanatory variables. The Bayesian classification of failing companies 
a was studied by a set of researchers as Gemela [24], Das and al. [20], Dwyer and al. [21], Gôssl [25] and Tasch [42].

\section{- Probabilistic Models}

The probabilistic models are the Logit model based on the logistic distribution and the Probit model based on the gaussian distribution. The several studies have focused on discriminant logistic analysis to predict the default of companies such as those conducted by Ohlson [34], Hunter and al. [31], Hensher and al.[28] while the Probit model has been studied by other researchers such as Zmijjewsji [44], Grover and al. [26] and Bunn and al.[18].

Due to the multitude of models, the determination of the expected credit loss $(E C L)^{1}$ as defined by the Basel Committee on Banking Supervision [12] becomes dependent on the models and techniques chosen for the elaboration of the rating system, which renders uncertain the calculation of the expected credit loss $(E C L)$, by the financial institutions, as a result of absence of standardization of the techniques used. In this case, the institutions can exploit the opportunities offered by the modelling to minimize the expected credit loss at the detriment of transparency and stability through the recourse of the arbitrage between the techniques and the models possible. This situation gives rise to a risk of models whose impact on the stability of banking system will have the same importance as the credit risk.

In this paper, we will show the uncertainty in the calculation of expected credit loss, generated by the multitude of models and the absence of standardization and it, by determining the expected loss of an $S M E$ s portfolio of a Moroccan bank. Indeed, we will study the impact of the modelling of probability of default $(P D)$ on the calculation of the expected credit loss and this, by using two versions of probabilistic models to predict the probability of default $(P D)$.

The Modelling in our study is based on the logistic regression because we will use the pure logistic regression and the logistic regression on the principal components to determine the probability of default per the rating class.

The rest of this paper is as follows, Section 2 is devoted to the calculation of the expected credit loss. We first give a definition of the credit risk. We then define the approach to calculate the unexpected and expected credit loss. We finally present, in this section, the construction approach of the scoring system and a probabilistic model that will be used. The third section is reserved to the empirical study. In this section, we will first analyze and describe the database used. Then we present and interpret the empirical results of the probability of default for each chosen model. We finally compare the expected credit loss calculated by the

1 Basel Committee on Banking Supervision, 2015, Guidance on credit risk and accounting for expected credit losses, Bank for International Settlements. chosen models.

\section{Calculation of the Expected Credit Loss $(E C L)$}

\subsection{Definition and Quantification of Credit Risk}

\subsubsection{Definition}

The credit risk of the banking portfolio is defined as the risk that counterparty will default for a one-year period. The notion of default means that the counterparty is unable to honor these commitments towards the establishment of credit. The incidents causing the default are multiple, but the most recurrent are:

- The downgrading outstanding debts in the bad debts ${ }^{2}$,

- The chronic overruns on lines of credit granted to clients,

- The accounts that have few transactions and the applications that have lapsed and that have not been renewed,

- The unfavorable echoes from the market, the sectoral difficulties and a significant fall in the level of activity.

Each credit relationship is associated with an actual or potential credit risk situation.

\subsubsection{The Credit Risk Situation}

The credit risk situation is composed of the following elements:

- Probability of default (PD): Probability that a counterpart falls at default in a horizon one year.

- Loss given default (LGD): The share, expressed as a percentage of the amount a bank loses when a borrower falls at default on a credit.

- Exposure at default (EAD): The total value to which a bank is exposed when a credit is at default.

- $\quad$ Maturity (M): The effective maturity of credit.

\subsubsection{The Losses Associated at the Risk of Credit}

We distinguish two types of losses:

- $\quad$ The Expected Loss $(E L)$

The expected loss is a percentage equal to the multiplication of the $P D$ and the $L G D$. The amount of the expected loss is equal to the multiplication of the expected loss $(E L)$ and the exposure at default $(E A D)$ :

Amount of the expected loss $\left(E L_{M}\right)$

$$
\begin{aligned}
& =P D \times L G D \times E A D \\
E L_{M}= & E L \times E A D
\end{aligned}
$$

2 In the Morocco, The downgrading outstanding debts in the bad debts is done in accordance with the provisions of BAM circular no. 19/G/2002 and Bank Al-Maghreb's instructions in the matter 
- $\quad$ The Unexpected Loss $(U L)$

The unexpected loss is the total loss from to the expected loss $(E L)$. It is calculated as a standard deviation from the mean at a certain confidence level $(1-\alpha)$. It is also called $V a R$ of credit.

\subsubsection{The Quantification of Credit Risk}

For the quantification of credit risk, the Basel Committee provides two categories of approaches for calculating the minimum capital requirements for credit risk $(K)$.

\subsubsection{The Standardized Approach}

Under the standardized approach, the bank must calculate the weighted assets. Indeed, a bank's total risk-weighted on-balance sheet equal the sum of the risk-weighted amounts of each asset it holds on-balance sheet.

The risk-weighted amount of an on-balance sheet asset is determined by multiplying its current book value of credit exposures by the risk weight $(\alpha)$ specified by the regulator. Exposures should be risk-weighted net of specific provisions.

$$
\begin{aligned}
& \text { Risk - weighted amount }{ }_{S T A} \\
& \quad=\alpha \times \text { credit exposures on } \\
& - \text { balance }
\end{aligned}
$$

The risk-weighting $(\alpha)$ is defined by type of claims (claims on sovereigns and central banks, claims on other official entities, claims on banks and securities firms, claims on corporates, claims included in the regulatory retail portfolios, claims secured by residential property, claims secured by commercial real estate, treatment of past due loans, higher-risk categories et other assets) ${ }^{3}$; and depending on the rating assigned to the counterparty by the external rating agencies.

The minimum capital requirements under the standard approach $\left(K_{S T A}\right)$ to cover the given counterparty credit risk exposure is defined as follows:

$$
K_{S T A}=\beta * \text { risk }- \text { weighted amount }{ }_{S T A}
$$

Where $: \beta$, is a minimum coefficient of solvability ${ }^{4}$

3 Annex 11, Basel Committee on Banking Supervision, 2006, International Convergence of Capital Measurement and Capital Standards, Bank for International Settlements

4 For Morocco this coefficient is fixed at 12\% as from January 2012

\subsubsection{The Internal Ratings-Based Approach $(I R B)$}

The Internal Rating-Based Approach is based on the four determinants mentioned above, which are the $P D$, $E A D, L G D$ and the Maturity $M$ to calculate of the unexpected loss $(U L)$ and expected loss $(E L)$ according of the regulatory requirements of Basel committee.

If the expected loss $(E L)$ is defined by the formula (1), the unexpected loss $(P U)$ is calculated by multiplying a coefficient $(\alpha)$ by the exposure at default $(E A D)$. The coefficient $(\alpha)$ is a function of the $P D, L G D$ and Maturity $(M)$. As a result:

$$
U L=f(P D, L G D, M) 5 \times E A D
$$

Furthermore, the banking regulations provide for two categories of Internal Rating-Based ${ }^{6}$ :

- The Internal Ratings-Based- foundation approach

Under the foundation approach, as a general rule, banks provide their own estimates of probability of default and rely on supervisory estimates for other risk components ( $L G D, E A D$ and $M$ ).

\section{- The Internal Ratings-Based- advanced approach}

Under the advanced approach, banks provide of their own estimates of $P D, L G D$ and $E A D$, and their own calculation of $M$.

\subsection{Calculation of the Expected Credit Loss}

Under the $I R B$ approach (foundation and advanced), the probability of default $(P D)$ is an important component in calculating the expected loss $(E L)$. Indeed, the aim is to determine the risk profile of the credit counterparty on the basis of qualitative and quantitative data through a discriminant analysis. The internal rating tool must enable credit counterparties to be classified as a function of their probability of default $(P D)$ and must predict customer failure. For this reason, we will present the process of conception of this type of classifier (rating tool):

\subsubsection{Presentation of the Process of Conception of a Rating Tool}

The following schema can summarize the process of conception of rating tool:
5 The formula of $f$ for SMEs is defined by Committee on Banking Supervision, 2006, International Convergence of Capital Measurement and Capital Standards, Bank for International Settlements at the paragraph level 272-273.

6 Basel Committee on Banking Supervision, 2006, International Convergence of Capital Measurement and Capital Standards, Bank for International Settlements at the paragraph level 245 

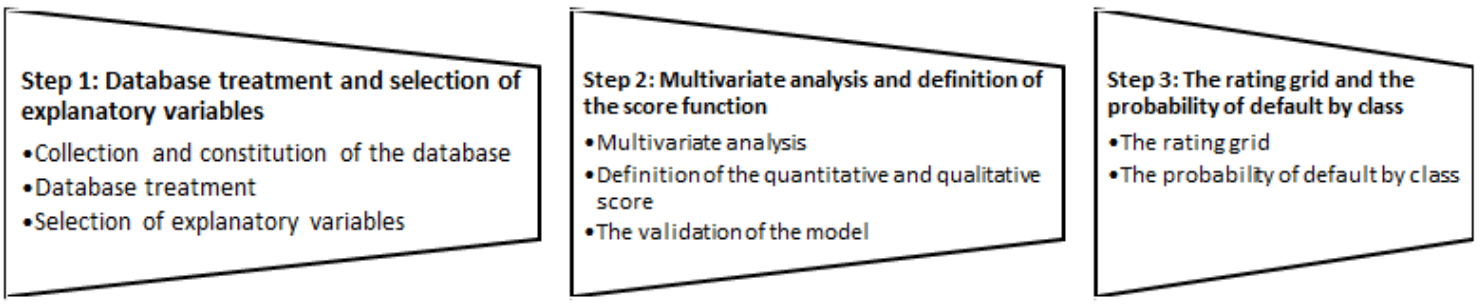

Figure 1. The process of conception of rating tool

In the following, we will present the approach, which we have adopted for the conception of ratings models; it is based respectively on logistic regression and logistic regression on principal components.

\subsubsection{Database Treatment}

The treatment of the database and the choice of explanatory variables are made according to the following schema:
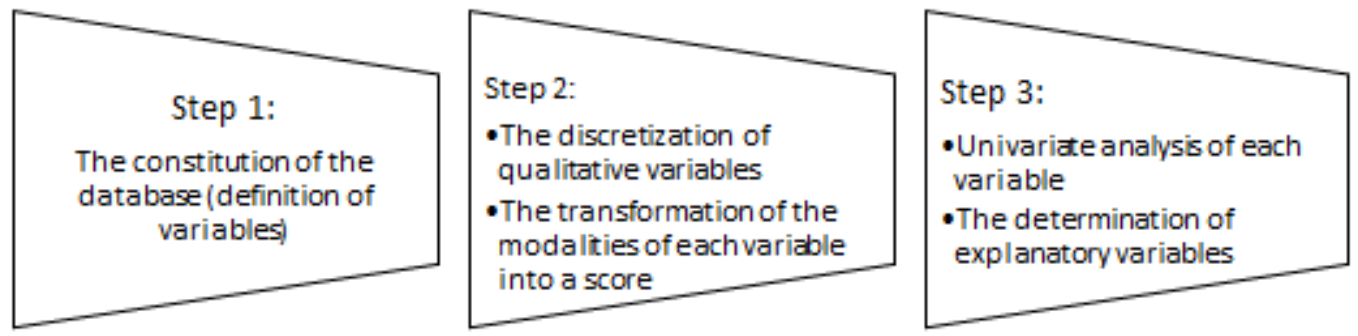

Figure 2. The treatment of the database and the choice of explanatory variables

The Constitution of the Database (Definition of Variables)

- $\quad$ The quantitative variables

The quantitative variables $\left(V_{j}\right), j=1, \ldots, 16$, are divided into 6 classes, defined as follows :

Table 1. The list of quantitative variables

\begin{tabular}{|c|c|}
\hline Class & The quantitative variables $\left(V_{j}, 1 \leq j \leq 16\right)$ \\
\hline$C_{1}:$ Activity & $\begin{array}{l}V_{1}=\text { Sales/ turnover }(\mathrm{ST}) \\
V_{2}=\text { Number of employees } \\
V_{3}=\text { Profit growth } \\
V_{4}=\text { Age of the company }\end{array}$ \\
\hline$C_{2}:$ Return of investment & $\begin{aligned} V_{5} & =\frac{\text { Net Profit }}{\text { Equity }} \\
V_{6} & =\frac{\text { Net Profit }}{\text { Sales } / \text { turnover }(S T)}\end{aligned}$ \\
\hline$C_{3}:$ Solvability & $\begin{aligned} V_{7} & =\frac{\text { Financial expenses }}{\text { Sales } / \text { turnover }(S T)} \\
V_{8} & =\frac{\text { DLMT }(\text { Debt long and meduim term })}{\text { Equity }} \\
V_{9} & =\frac{\text { Net Debt }}{\text { Equity }}\end{aligned}$ \\
\hline$C_{4}:$ Liquidity & $V_{10}=\frac{(\text { Accounts Receivable }+ \text { assets } . \text { Cash })}{(\text { Liabilities. Cash }+ \text { working capital requirements }- \text { Accounts Receivable }- \text { inventory })}$ \\
\hline$C_{5}:$ financial structure & $\begin{aligned} V_{11} & =\frac{\text { Working Capital }}{\text { Current Assets }} \\
V_{12} & =\frac{\text { Equity }}{\text { Total Assets }}\end{aligned}$ \\
\hline$C_{6}:$ Turnover & $\begin{aligned} V_{13} & =\frac{\text { Sales } / \text { turnover }(S T)}{\text { Net fixed assets }+W C R} \text { where WCR is working capital requirements } \\
V_{14} & =\frac{\text { inventory }}{\text { Sales } / \text { turnover }(S T)} \\
V_{15} & =\frac{\text { Accounts } \text { Receivable }}{\text { Sales } / \text { turnove }(S T)} \\
V_{16} & =\frac{\text { Accounts Payable }}{\text { Total purchase }}\end{aligned}$ \\
\hline
\end{tabular}

\section{- The qualitative variables}

The qualitative variables $\left(q_{m}, 1 \leq m=1, \ldots, 19\right)$ are grouped by theme $T_{k}, k=1, \ldots, 6$, as follows: 
Table 2. The list of qualitative variables

\begin{tabular}{|c|c|}
\hline Theme & The qualitative variables $\left(q_{m}\right)$ \\
\hline$T_{1}:$ The sector of activity & $\begin{array}{l}\left(q_{1}=q_{1 T 1}\right): \text { Sector fault rate } \\
\left(q_{2}=q_{2 T 1}\right): \text { Regulatory impact next year } \\
\left(q_{3}=q_{3 T 1}\right): \text { Exposure to natural risk }\end{array}$ \\
\hline $\begin{array}{l}T_{2}: \text { The company's positioning and } \\
\text { competition }\end{array}$ & $\begin{array}{l}\left(q_{4}=q_{1 T 2}\right): \text { Competitive position and intensity } \\
\left(q_{5}=q_{2 T 2}\right): \text { Barriers and new entrants } \\
\left(q_{6}=q_{3 T 2}\right): \text { International Competition }\end{array}$ \\
\hline $\begin{array}{l}T_{3}: \text { The concentration and position of the } \\
\text { counterparty vis-à-vis its suppliers and } \\
\text { customers }\end{array}$ & $\begin{array}{l}\left(q_{7}=q_{1 T 3}\right): \text { Customer concentration } \\
\left(q_{8}=q_{2 T 3}\right): \text { Supplier concentration } \\
\left(q_{9}=q_{3 T 3}\right): \text { Positions vis-à-vis suppliers and customers }\end{array}$ \\
\hline$T_{4}$ : Quality and management structure & $\begin{array}{l}\left(q_{10}=q_{1 T 4}\right): \text { Succession planning and business continuity } \\
\left(q_{11}=q_{2 T 4}\right): \text { Experience Chairman } \\
\left(q_{12}=q_{3 T 4}\right): \text { Seniority of the principal operational staff } \\
\left(q_{13}=q_{4 T 4}\right): \text { Capital distribution } \\
\left(q_{14}=q_{5 T 4}\right): \text { Compliance with the accounting documents delivery schedule } \\
\left(q_{15}=q_{6 T 4}\right): \text { Performance last crisis } \\
\left(q_{16}=q_{7 T 4}\right): \text { Existence of agent's insurance. }\end{array}$ \\
\hline$T_{5}$ : The company's history with banking & $\begin{array}{l}\left(q_{17}=q_{1 T 5}\right): \text { Number of payment incidents in the last } 12 \text { months } \\
\left(q_{18}=q_{2 T 5}\right): \text { Percentages of unpaid bills over the last } 12 \text { months }\end{array}$ \\
\hline$T_{6}$ : Relations with banks & $\left(q_{19}=q_{1 T 6}\right):$ Number of banks related to the company \\
\hline
\end{tabular}

Discretization of Qualitative Variables and Their Transformation into a Score

\section{- Discretization of qualitative variables}

The qualitative variables $\left(q_{m}\right), 1 \leq m \leq 19$ are discretized into modalities. The number of modalities can be equal at 3 or 5 modalities. The rule of the modalities choice is based on the logical relationship between modalities and default.

- Transformation of quantitative variable into score

Let $\left(M_{q_{m}, l}\right), l=1, \ldots, l_{q_{m}}$, be the modalities of the qualitative variable $\left(q_{m}\right)$ and $\left(l_{q_{m}}\right)$ defines the number of modalities $\left(l_{q_{m}} \in\{3,5\}\right)$. For each modality, the score varies between 0 and 100 points with a jump of 50 points per modality for the variables at three modalities and a jump of 25 points for the variables at five-modalities. The score taken by the modalities is:

* Variables at three modalities : [0, 50,100]

Example: the modalities relating to the sector default rate are : 1 - below average, 2- equal to average, 3- above average. In this case, the scores given are respectively: 100, 50,0 .

* Variables at five modalities : [0, 25, 50, 75,100]

Example: the modalities relating to natural risk are:1- No risk, 2- Low risk and the adequate crisis plan, 3- High risk and the adequate crisis plan, 4- Low risk without crisis plan, 5- High risk without crisis plan. In this case, the scores given are respectively: 100, 75, 50, 25, 0 .

The assessment of the logical relationship between the modalities of each variable and the default is determined on the basis of expert opinion.

Univariate analysis and the determination of explanatory variables

\section{- Univariate analysis}

The objective of univariate analysis is to determine the relationship between a company's default and each of its quantitative and qualitative variables. The default is modeled by a binary variable $Y$ defined as follows:

$$
Y=\left\{\begin{array}{c}
1 \text { if the company is healthy } \\
0 \text { if the company is in default }
\end{array}\right.
$$

The relationship between the variable $Y$ to be explained and the explanatory variables $V_{j}$ and $q_{m}$ is determined by the logistic regression model.

Indeed, the definition (4) shows that the variable $Y$ is a Bernoulli variable which takes the values 0 and 1 of parameter $p$ with $P(Y=1)=p$ and $P(Y=0)=1-p$. Therefore, the formula (4) can be written in probability as follows:

$$
P\left(Y=y_{i}\right)=p^{y_{i}}(1-p)^{1-y_{i}}
$$

The logistic regression relationship consists in defining a relationship between $Y$ and a logistic probability $(p)$ defined from the variables $\left(V_{j}\right)$ and $\left(q_{m}\right)$. Indeed, we need to make a logistical transformation (Logit) to bind the dependent variable $Y$ to each variable among the quantitative variables $\left(V_{j}\right), \mathrm{j}=1, \ldots, 16$ and qualitative variables $\left(q_{m}\right), m=1, \ldots, 19$.

For each quantitative variable $V_{j}$ or qualitative $q_{m}$ the relationship between the default and the variables studied is defined by the probability:

$$
p_{0, j}=P\left(Y=1 / V_{j}\right) \text { or } p_{0, q_{m}}=P\left(Y=1 / q_{m}\right)
$$

Indeed, the modelling of $Y$ conditionally to the quantitative variable $V_{j}$ or qualitative variable $q_{m}$, is defined by the model:

$$
Y=p_{o}+\varepsilon
$$

With $p_{0}=P\left(Y=1 / V_{j}\right)\left(\right.$ or $\left.p_{0}=P\left(Y=1 / q_{m}\right)\right)$

* The modelling of the probability $p_{0}$

We will only present the univariate analysis of the 
quantitative variables $V_{j}$ since we will proceed in the same way for the analysis of the qualitative variables $q_{m}$.

Indeed, for each company ( $i$ ), the value of the quantitative variable $V_{j}$ is $v_{i j}$ and let $p_{0 i}$ be the probability that the company $(i)$ is healthy. Indeed, $p_{0 i}$ is defined by $P\left(Y_{i}=1 / V_{j}=v_{i j}\right)$ with:

$$
Y_{i}=\left\{\begin{array}{c}
1 \text { if the company }(i) \text { is healthy } \\
0 \text { if the company }(i) \text { is in default }
\end{array}\right.
$$

Thus, the formula (6) for company $(i)$ is written:

$$
y_{i}=p_{0 i}+\varepsilon_{i}
$$

First, we will define the ratio $\frac{p_{0 i}}{1-p_{0 i}}$ noted the Oddos of $p_{0 i}$ :

$$
\begin{aligned}
\operatorname{Oddos}\left(p_{0 i}\right)= & \frac{p_{0 i}}{1-p_{0 i}} \\
& =\frac{P\left(Y_{i}=1 / V_{j}=v_{i j}\right)}{1-P\left(Y_{i}=1 / V_{j}=v_{i j}\right)}
\end{aligned}
$$

Consequently, the logistic regression model establishes a linear regression relationship between $\ln \left(\frac{p_{0 i}}{1-p_{0 i}}\right)$ and $v_{i j}$ as follows:

$$
\operatorname{Logit}\left(p_{0 i}\right)=\ln \left(\frac{p_{0 i}}{1-p_{0 i}}\right)=\beta_{0}+\beta_{1} \times v_{i j}
$$

where from $p_{0 i}=\frac{e^{\beta_{0}+\beta_{1} \times v_{i j}}}{1+e^{\beta_{0}+\beta_{1} \times v_{i j}}}$

Therefore, the formula (6) and the associated probability $8 p_{o}$ can be written:

$$
\left\{\begin{array}{c}
Y=p_{0}+\varepsilon \\
p_{0}=\frac{e^{\beta_{0}+\beta_{1} \times V_{j}}}{1+e^{\beta_{0}+\beta_{1} \times V_{j}}}
\end{array}\right.
$$

* The estimation of parameter

Let $Y_{i}$ be the random variable that models the company's default $(i)$. The conditional variable $\left(Y_{i} / V_{j}=\right.$ $v_{j i}$ ) can be written in probability as follows:

$$
\begin{aligned}
& P\left(Y_{i} / V_{j}=v_{i j}\right)=P\left(Y_{i}=y_{i} / V_{j}=v_{i j}\right)= \\
& p_{0 i} y_{i} \times\left(1-p_{0 i}\right)^{\left(1-y_{i}\right)} \text { with } y_{i}=0 \text { or } 1
\end{aligned}
$$

* The likelihood function:

The likelihood function of $n$ enterprise is defined by:

$$
\begin{aligned}
L=\prod_{i=1}^{n} P\left(Y_{i} / V_{j}\right. & \left.=v_{i j}\right) \\
& =\prod_{i=1}^{n}\left(1-p_{0 i}\right)^{\left(1-y_{i}\right)} \times p_{0 i} y_{i} \\
L & =\prod_{i=1}^{n}\left(\frac{e^{\beta_{0}+\beta_{1} \times v_{i j}}}{1+e^{\beta_{0}+\beta_{1} \times v_{i j}}}\right)^{y_{i}} \\
& \times\left(1-\frac{e^{\beta_{0}+\beta_{1} \times v_{i j}}}{1+e^{\beta_{0}+\beta_{1} \times v_{i j}}}\right)^{\left(1-y_{i}\right)}
\end{aligned}
$$

The Loglikelihood function $(L L)$

$$
\begin{aligned}
L L=\sum_{i=1}^{n} y_{i} \times \ln & \left(\frac{e^{\beta_{0}+\beta_{1} \times v_{i j}}}{1+e^{\beta_{0}+\beta_{1} \times v_{i j}}}\right) \\
& +\sum_{i=1}^{n}\left(1-y_{i}\right) \times \ln (1 \\
& \left.-\frac{e^{\beta_{0}+\beta_{1} \times v_{i j}}}{1+e^{\beta_{0}+\beta_{1} \times v_{i j}}}\right)
\end{aligned}
$$

$$
\begin{aligned}
& L L=\sum_{i=1}^{n} \ln \left(\frac{1}{1+e^{\beta_{0}+\beta_{1} \times v_{i j}}}\right) \\
& +y_{i}\left(\ln \left(\frac{e^{\beta_{0}+\beta_{1} \times v_{i j}}}{1+e^{\beta_{0}+\beta_{1} \times v_{i j}}}\right)\right. \\
& \left.-\ln \left(\frac{1}{1+e^{\beta_{0}+\beta_{1} \times v_{i j}}}\right)\right)
\end{aligned}
$$

$$
L L=\sum_{i=1}^{n} \ln \left(\frac{1}{1+e^{\beta_{0}+\beta_{1} \times v_{i j}}}\right)+y_{i} \times\left(\beta_{0}\right.
$$

Let us note $\beta=\left(\beta_{0}, \beta_{1}\right)$ so the estimate of $\beta$ is the determination of $\hat{\beta}$ which maximizes the likelihood function and consequently maximizes the Loglikelihood function $(L L)$.

The maximization of $L L$ will be done by solving the equation system determined by the following conditions:

$$
\frac{\partial L L}{\partial \beta}=0 \text { and } \frac{\partial^{2} L L}{\partial^{2} \beta}<0
$$

Three numerical algorithms are used to solve this problem, which are the Newton-Raphson algorithm, the score method and the Berndt-Hall-Hall-Hausman method.

Testing of the significance of the coefficients (test de Wald)

The testing of the significance of the coefficient $\beta_{1}$, is established by the Wald test. The Wald test is obtained by testing the hypothesis $H_{0}$ formulated as follows:

$$
\left\{\begin{array}{l}
H_{0}: \beta_{1}=0 \\
H_{1}: \beta_{1} \neq 0
\end{array}\right.
$$

The Wald test is based to the following ratio:

$$
W_{1}=\hat{\beta}_{1}^{2} / \hat{\sigma}_{\hat{\beta}_{1}}^{2}
$$

The ratio, under the hypothesis $H_{0}$, will folow a $\chi^{2}$ with one degree of freedom. We reject $H_{0}$ if $W_{1}>\chi_{1}^{2}$.

\section{* discriminatory power (power stat)}

The discriminatory power represents the model's ability to predict future situations. We will use the $R O C$ curve to determine the discriminatory power of each variable $V_{j}$ and $q_{m}$. The determination of the ROC curve will be done from the classification table of the sample of estimation of the variable $Y$ which is presented as follows: 
Table 3. The classification table

\begin{tabular}{|c|c|c|}
\hline & Healthy $(Y=1)$ & Default $(Y=0)$ \\
\hline Healthy $(Y=1)$ & True Healthy $(T H)$ & False Healthy $(F H)$ \\
\hline Default $(Y=0)$ & False Default $(F D)$ & True Default (TD) \\
\hline
\end{tabular}

One indicates by sensitivity $(S V)$, the proportion of the healthy companies classified well: $S V=\frac{T H}{T H+F H}$ and by specificity $(S P)$, the proportion of the de companies is in default, classified well: $S P=\frac{F D}{F D+\mathrm{T} D}$

If one varies the "probability threshold" from which it is considered that a company must be regarded as healthy, the sensitivity and specificity varies. The curve of the points $(1-S P, S V)$ is the $R O C$ curve.

\section{- The determination of explanatory variables}

To determine the explanatory variables to be retained for modelling, we will carry out a univariate logistic regression analysis for each variable in the chosen list. The choice of variables to be retained for the modelling is based on the discriminatory power of each variable.

The discriminatory power is determined by using the area under the $R O C$ curve and the Accuracy ratio $(A R)$.

* Definition of the area under the $\boldsymbol{R O C}$ curve $(\boldsymbol{A U C})$ and the Accuracy ratio $(\boldsymbol{A R})$

$\checkmark \quad$ The area under the $R O C$ curve $(A U C)$

The area under the $R O C$ curve $(A U C)$ provides an overall measure of model fit (Bewick, Cheek, \& Ball,[45]). The $A U C$ varies from 0,5 (predictive capacity absence for the model) to 1 (perfect predictive aptitude for the model).

\section{$\checkmark \quad$ Accuracy ratio $(A R)$}

The accuracy ratio is defined by the relationship:

$$
A R=2 A U C-1
$$

The $A R$ takes values between 0 and 1 .

\section{* Determination of explanatory variables \\ $\checkmark \quad$ The decision rules}

The variables that verify the following two characteristics will be retained:

- $\quad$ The Area Under the ROC Curve $(A U C)$ is superior to $60 \%$ and accuracy ratio $(A R)$ is superior to $20 \%$;

- $\quad$ The relationship established between the factor and the default rate must be logical. This qualification is based on expert opinion.

\section{$\checkmark \quad$ Strongly correlated variables}

After selecting the explanatory variables on the basis of the decision rules mentioned above, we will study the correlation between the selected variables. The study of correlations makes it possible to eliminate strongly correlated variables. Indeed, if two or more variables have a correlation coefficient superior to $0,5(\rho \geq 0,5)$ then the variable that represents the greatest $A U C$ will be selected.

\subsubsection{Multivariate Discriminant Analysis and Definition} of the Score Function

\subsection{Multivariate Discriminant Analysis}

In this paragraph, we will present the modeling of the relationship between quantitative and qualitative variables and defect, through pure logistic regression and logistic regression on main components and we will then present the tests for assessing the fit of the multivariate model.

\section{- The pure logistic regression}

Let $X_{j}, j=1, \ldots, J$ and $T_{k}, k=1, \ldots, 6$ be the respectively the quantitative and qualitative variables retained by the univariate analysis.

The objective of multivariate discriminant analysis by the pure logistic regression, is to study the relationship between the variable to be explained $Y$ and the explanatory variables $X_{j}, j=1, \ldots, J$ and $T_{k}, k=1, \ldots, 6$. In this case, we will separate the modelling of the quantitative and qualitative variables. Indeed, the Models can be formulated by the following relationships:

\section{$\checkmark \quad$ The quantitative model}

$$
Y=f_{1}\left(X_{1}, X_{2}, \ldots, X_{J}\right)+\epsilon
$$

\section{$\checkmark \quad$ The qualitative model}

$$
Y=f_{2}\left(T_{1}, T_{2}, \ldots, T_{6}\right)+\epsilon
$$

where $f_{1}$ and $f_{2}$ are the logistics probabilities.

Let $(n)$ be the size of the company sample used for modelling and $X=\left(x_{i j}\right), 1 \leq i \leq n, 1 \leq j \leq J$, the matrix whose columns are $X_{j}, 1 \leq j \leq \mathrm{J}$ and let $T=\left(t_{i k}\right), 1 \leq$ $i \leq n, 1 \leq k \leq 6$ be the matrix whose columns are $T_{k}, 1 \leq k \leq 6$.

\section{* Presentation of the model}

The objective of the modelling is to express the variable $Y$ by the following model:

$$
Y=p+\varepsilon
$$

With $p=P\left(Y=1 / X_{1}, \cdots, X_{J}, T_{1}, \cdots, T_{6}\right)$

Indeed, let $\left(x_{i 1}, \cdots, x_{i j}\right)$ and $\left(t_{i 1}, \cdots, t_{i 6}\right)$ be the quantitative and qualitative data, of the company $(i)$ and $y_{i}$ the realization of $Y_{i}$ for this company then $y_{i}$ is written:

$$
y_{i}=p_{i}+\varepsilon_{i}
$$

Where $p_{i}=P\left(Y_{i}=1 / x_{i 1}, \cdots, x_{i j}, t_{i 1}, \cdots, t_{i 6}\right)$ The Logit transformation has the following form:

$$
\begin{aligned}
& \operatorname{Logit}\left(p_{i}\right)=\ln \left(\frac{p_{i}}{1-p_{i}}\right) \\
& =\ln \left(\frac{P\left(Y_{i}=1 / x_{i 1}, \cdots, x_{i J}, t_{i 1}, \cdots, t_{i 6}\right)}{P\left(Y_{i}=0 / x_{i 1}, \cdots, x_{i J}, t_{i 1}, \cdots, t_{i 6}\right)}\right) \\
& =\ln \left(\frac{P\left(Y_{i}=1 / x_{i 1}, \cdots, x_{i J}, t_{i 1}, \cdots, t_{i 6}\right)}{1-P\left(Y_{i}=1 / x_{i 1}, \cdots, x_{i J}, t_{i 1}, \cdots, t_{i 6}\right)}\right)
\end{aligned}
$$


Thus, $\operatorname{Logit}(p)$ can be written:

$$
\begin{aligned}
& \operatorname{Logit}(p)=\ln \left(\frac{p}{1-p}\right) \\
& =\ln \left(\frac{P\left(Y=1 / X_{1}, \cdots, X_{J}, T_{1}, \cdots, T_{6}\right)}{1-P\left(Y=1 / X_{1}, \cdots, X_{J}, T_{1}, \cdots, T_{6}\right)}\right)
\end{aligned}
$$

* The quantitative modelling of $Y$ by the probability $p_{1}$

The modelling of $Y$ conditional only on quantitative data is defined by the model:

$$
Y=p_{1}+\varepsilon
$$

where $p_{1}=P\left(Y_{i}=1 / X_{1}, \cdots, X_{J}\right)$

Let $\left(x_{i 1}, \cdots, x_{i J}\right)$ be the quantitative data of the company ( $i$ ) which represent the realizations of the variables $\left(X_{1}, \cdots, X_{J}\right)$ by the company $(i)$ and $y_{i}$ the realization of $Y_{i}$ for this company then $y_{i}$ is written:

$$
y_{i}=p_{1 i}+\varepsilon_{i}
$$

Where $p_{1 i}=P\left(Y_{i}=1 / x_{i 1}, \cdots, x_{i f}\right)$

To determine the expression of $p_{1 \mathrm{i}}$ by the logistic regression model, we will first define the Oddos represented by the ratio $\frac{p_{1 i}}{1-p_{1 i}}$. Hence:

$$
\operatorname{Oddos}\left(p_{1 i}\right)=\frac{p_{1 i}}{1-p_{1 i}}=\frac{P\left(Y_{i}=1 / x_{i 1}, \cdots, x_{i J}\right)}{1-P\left(Y_{i}=1 / x_{i 1}, \cdots, x_{i j}\right)}
$$

Therefore, we can write the model:

$$
\begin{aligned}
\operatorname{Logit}\left(p_{1 i}\right)=\ln & \left(\frac{p_{1 i}}{1-p_{1 i}}\right) \\
& =\beta_{0}+\beta_{1} \times x_{i 1}+\beta_{2} \times x_{i 2}+\cdots \\
& +\beta_{J} \times x_{i J}=\beta x_{i}{ }^{\prime}
\end{aligned}
$$

Where

$$
\beta=\left(\beta_{0}, \ldots, \beta_{J}\right)
$$

and $x_{i}{ }^{\prime}=\operatorname{Transpose}\left(1, x_{i 1}, \cdots, x_{i J}\right)$, so:

$$
p_{1 i}=\frac{e^{\beta x_{i}{ }^{\prime}}}{1+e^{\beta x_{i}{ }^{\prime}}}
$$

Let be $X^{\prime}=$ Transpose $\left(1, x_{1}, \cdots, x_{J}\right)$ then $p_{1}$ and $Y$ can be written

$$
\left\{\begin{array}{c}
p_{1}=\frac{e^{\beta X^{\prime}}}{1+e^{\beta X^{\prime}}} \\
Y=p_{1}+\varepsilon
\end{array}\right.
$$

\section{* The estimation of parameters}

Let $y_{i}$ be the realization of $Y_{i}$ related the company (i), the conditional variable $\left(Y_{i} / x_{i 1}, \cdots, x_{i j}\right)$ can be written in probability as follows:

$$
\begin{gathered}
P\left(Y_{i}=y_{i} / x_{i 1}, \cdots, x_{i j}\right)=p_{1 i}{ }^{y_{i}} \times \\
\left(1-p_{1 i}\right)^{\left(1-y_{i}\right)} \text { where } y_{i}=1 \text { or } y_{i}=0
\end{gathered}
$$

* The likelihood function

The likelihood function of $n$ enterprise is defined by:

$$
\begin{gathered}
L=\prod_{i=1}^{n} P\left(Y_{i}=y_{i} / x_{i 1}, \cdots, x_{i J}\right) \\
=\prod_{\substack{i=1 \\
n}}^{n}\left(1-p_{1 i}\right)^{\left(1-y_{i}\right)} \\
\times p_{1 i}^{y_{i}} \\
L=\prod_{i=1}^{n}\left(\frac{e^{\beta x_{i}{ }^{\prime}}}{1+e^{\beta x_{i}^{\prime}}}\right)^{y_{i}} \times\left(1-\frac{e^{\beta x_{i}^{\prime}}}{1+e^{\beta x_{i}^{\prime}}}\right)^{\left(1-y_{i}\right)}
\end{gathered}
$$

- The loglikelihood function (LL)

$$
\begin{gathered}
L L=\sum_{i=1}^{n} y_{i} \times \ln \left(\frac{e^{\beta x_{i}{ }^{\prime}}}{1+e^{\beta x_{i}{ }^{\prime}}}\right) \\
+\sum_{i=1}^{n}\left(1-y_{i}\right) \times \ln (1 \\
\left.-\frac{e^{\beta x_{i}{ }^{\prime}}}{1+e^{\beta x_{i}{ }^{\prime}}}\right) \\
L L=\sum_{i=1}^{n} \ln \left(\frac{1}{1+e^{\beta x_{i}^{\prime}}}\right)+y_{i} \beta x_{i}{ }^{\prime}
\end{gathered}
$$

Let us note $\beta=\left(\beta_{0}, \beta_{1}, \ldots, \beta_{J}\right)$ so the estimate of $\beta$ is to determine $\hat{\beta}$ wich maximizes the likelihood function and consequently maximizes the loglikelihood function $(L L)$.

The maximization of $L L$ will be done by solving the equation system determined by the following conditions:

$$
\frac{\partial L L}{\partial \beta}=0 \text { and } \frac{\partial^{2} L L}{\partial^{2} \beta}<0
$$

Also, this problem is solved numerically, by the Newton-Raphson algorithm, the score method or the Berndt-Hall-Hall-Hausman method.

The quantitative score function :

The estimation of $\beta$ allows determining the quantitative score function $S_{1}$ that is written:

$$
S_{1}=\hat{\beta} X^{\prime}
$$

Hence, the probability $p_{1}$ is estimated by:

$$
p_{1}=\frac{e^{S_{1}}}{1+e^{S_{1}}}
$$

The qualitative modelling of $\boldsymbol{Y}$ by the probability $\boldsymbol{p}_{2}$

The objective of qualitative modelling is to determine the relationship between the variable $Y$ and the themes $T_{i}$. The values taken by the theme $T_{i}$ is a linear weighting of the qualitative variables $q_{m}$ that compose it, noted, $q_{m T i}, 1 \leq m \leq \mathrm{p}$. Indeed, $T_{i}$ is defined as follows:

$$
T_{i}=\alpha_{1} q_{1 T i}+\cdots+\alpha_{p} q_{p T i}
$$


where

$\checkmark \quad \alpha_{m}=0$ if the variable $q_{m T i}$ is not explanatory

$\checkmark \quad$ For explanatory variables $q_{m T i}$, the associated $\alpha_{m}$ weights are determined by weight simulations that maximize the discriminatory power of the theme $T_{i}$ (max $A U C$ ) by a logistic regression between the variable $Y$ and the them $T_{i}$.

The modelling of $Y$ conditional on qualitative data only, is defined by the model:

$$
Y=p_{2}+\varepsilon
$$

with $p_{2}=P\left(Y_{i}=1 / T_{1}, \cdots, T_{6}\right)$

Let $\left(t_{i 1}, \cdots, t_{i 6}\right)$ be the qualitative data of the company $(i)$ and $y_{i}$ the realization of $Y_{i}$ for this company then $y_{i}$ is written:

$$
y_{i}=p_{2 \mathrm{i}}+\varepsilon_{i}
$$

Where $p_{2 \mathrm{i}}=P\left(Y_{i}=1 / t_{i 1}, \cdots, t_{i 6}\right)$

In this case, the oddos of the probability $p_{2 \mathrm{i}}$ are written:

$$
\operatorname{Oddos}\left(p_{2 i}\right)=\frac{p_{2 \mathrm{i}}}{1-p_{2 \mathrm{i}}}=\frac{P\left(Y_{i}=1 / t_{i 1}, \cdots, t_{i 6}\right)}{1-P\left(Y_{i}=1 / t_{i 1}, \cdots, t_{i 6}\right)}
$$

Therefore, we can write the model:

$$
\begin{aligned}
\operatorname{Logit}\left(p_{2 \mathrm{i}}\right)=\ln & \left(\frac{p_{2 \mathrm{i}}}{1-p_{2 \mathrm{i}}}\right) \\
& =\tau_{0}+\tau_{1} \times t_{i 1}+\cdots \cdots+\tau_{6} \times t_{i 6} \\
& =\tau t_{i}{ }^{\prime}
\end{aligned}
$$

where $\quad \tau=\left(\tau_{0}, \ldots, \tau_{n}\right)$ and

$t_{i}{ }^{\prime}=$ Transpose $\left(1, t_{i 1}, \cdots \cdots, t_{i 6}\right)$

thus:

$$
p_{2 \mathrm{i}}=\frac{e^{\tau t_{i}^{\prime}}}{1+e^{\tau t_{i}{ }^{\prime}}}
$$

Let be $T^{\prime}=$ Transposé $\left(1, t_{1}, \cdots, t_{6}\right)$ then $p_{2}$ and $Y$ can be written :

$$
\left\{\begin{array}{c}
p_{2}=\frac{e^{\tau T^{\prime}}}{1+e^{\tau T^{\prime}}} \\
Y=p_{2}+\varepsilon
\end{array}\right.
$$

For the estimation of $\hat{\tau}=\left(\hat{\tau}_{0}, \ldots, \hat{\tau}_{n}\right)$, the same procedure presented for the quantitative model will be used.

* The qualitative score function :

The estimation of $\tau$ allows determining the qualitative score function $S_{2}$ that is written:

$$
S_{2}=\hat{\tau} T^{\prime}
$$

Hence, the probability $p_{2}$ is estimated by:

$$
p_{2}=\frac{e^{S_{2}}}{1+e^{S_{2}}}
$$

\section{- The logistic regression on the principal components}

The principal components analysis $(P C A)$ is a technique based on the reduced of the explanatory variables by transforming the correlated variables into uncorrelated variable, which explain the maximum amount of variance, called the principal components $(P C S)$, this technique was introduced by Karl Pearson in the early 20th century, and developed by Harold Hötteling in 1933.

\section{* The principal components analysis $(\boldsymbol{C P A})$}

Let $\left(Z_{j}, 1 \leq j \leq p\right)$ be the $p$ explanatory variables (quantitative and qualitative) and let $\left(z_{i j}\right)_{n \times p}$ be the $n p$ realization of these variables. Let $Z=\left(z_{i j}\right)_{n \times p}$ be the matrix of these realizations. The column vectors of the matrix $Z$ are $z_{.1}, z_{.2}, z_{.3} \ldots, z_{. p}$ who represent the realization of each variable $Z_{j}$.

Let us note $S=\left(s_{j k}\right)_{p \times p}$ the covariance matrix of the variables $\left(Z_{j}, 1 \leq j \leq p\right)$ and let $\left(\lambda_{1}, \lambda_{2}, \lambda_{3}, \ldots . \lambda_{p}\right)$ and $\left(F_{1}, F_{2}, \ldots, F_{p}\right)$ be, respectively, the eigenvalues and the eigenvectors of the matrix $S$. We designated by $L$ the matrix whose columns $L_{i}, i=1, \ldots, p$ are the principal components defined by $L=Z F$ with $F=\left(f_{j k}\right)_{p \times p}$ being the matrix which has as columns the eigenvectors $\left(F_{\mathrm{i}}\right)$ of the matrix $S$.

The decomposition into principal component makes it possible to express the vectors $Z_{j}$ into reduced number of principal components $Z_{j}=\sum_{k=1}^{s} L_{k} f_{j k}, \mathrm{j}=1 \ldots . . \mathrm{p}$, which represents a high percentage of cumulative variation $(\mathrm{CV})$ given by the following formula:

$$
C V=\left[\frac{\sum_{j=1}^{s} \lambda_{j}}{\sum_{j=1}^{p} \lambda_{j}} \times 100\right], s \leq p
$$

The average variation $V_{m}$ is defined by:

$$
V_{m}=\left[\frac{\sum_{j=1}^{p} \lambda_{j}}{p} \times 100\right]
$$

* The logistic regression on the principal components

The logistic regression on the $p$ principal components $L_{i}$ is equivalent to the logistic regression on the explanatory variables $Z_{j}, \mathrm{j}=1, \ldots, \mathrm{p}$. Indeed, let $z_{j i}$, $i=1, \ldots . n$ be the realizations of the variables $Z_{j}$ hence $z_{j i}=\sum_{k=1}^{p} L_{k i} f_{j k}$ so

$$
\begin{array}{r}
p_{i}=\frac{e^{\left(\beta_{0}+\sum_{j=1}^{p} \beta_{j} z_{j i}\right)}}{1+e^{\left(\beta_{0}+\sum_{j=1}^{p} \beta_{j} z_{j i}\right)}}=\frac{e^{\left(\beta_{0}+\sum_{j=1}^{p} \Sigma_{k=1}^{p} l_{k i} f_{j k} \beta_{j}\right)}}{1+e^{\left(\beta_{0}+\sum_{j=1}^{p} \Sigma_{k=1}^{p} l_{k i} f_{j k} \beta_{j}\right)}}= \\
\frac{e^{\left(\beta_{0}+\sum_{k=1}^{p} l_{k i} \gamma_{k}\right)}}{1+e^{\left(\beta_{0}+\sum_{k=1}^{p} l_{k i} \gamma_{k}\right)}}
\end{array}
$$

with $\gamma_{k}=\sum_{j=1}^{p} f_{j k} \beta_{j},(k=1, \ldots p)$

In order to improve the quality of the model in the case of collinearity, we will use a reduced number of $(s)$ principal components for modelling the variable $Y$. Indeed, the formula (20) becomes:

$$
y_{i}=p_{i(s)}+\varepsilon_{i(s)}
$$

Hence

$$
p_{i(s)}=\frac{e^{\left(\beta_{0}+\sum_{k=1}^{S} l_{k i} \gamma_{k}\right)}}{1+e^{\left(\beta_{0}+\sum_{k=1}^{S} l_{k i} \gamma_{k}\right)}}
$$


In our study, the number $(s)$ is defined as the number of components whose cumulative variation is superior to $70 \%$.

For the $C P A$, the quatitative variables and the qualitative variables are modeled simultaneously to determine the probability $p_{i(s)}$

\section{- Assessing the fit of the multivariate model:}

To assess the fit of the multivariate quantitative and qualitative models, we will proceed as follows:

* Testing of the significance of the coefficients

Let be the logistics model defined by:

$$
y_{i}=p_{i}+\varepsilon_{i}
$$

With $\quad p_{i}=\frac{e^{\beta H^{\prime}}}{1+e^{\beta H^{\prime}}} \quad, \quad \beta=\left(\beta_{0}, \ldots, \beta_{m}\right) \quad$ and $\quad H^{\prime}=$ $\operatorname{tr}\left(1, H_{1}, \ldots, H_{m}\right)$

The significance of the regression parameters $\left(\beta_{1}, \ldots, \beta_{m}\right)$ consists in testing the individual and overall significance of the model parameters:

Testing of the individual significance (Test de Wald)

To assess individual significance, the hypothesis to be tested is:

$$
\left\{\begin{array}{l}
H_{0}: \beta_{i}=0 \\
H_{1}: \beta_{i} \neq 0
\end{array}\right.
$$

The testing for the significance of the coefficient $\beta_{i}$, is established by the Wald test based to the following ratio :

$$
W_{i}=\frac{\hat{\beta}_{i}^{2}}{\hat{\sigma}\left(\hat{\beta}_{i}\right)^{2}}
$$

The ratio, under the hypothesis $H_{0}$, will folow a $\chi^{2}$ with one degree of freedom. We reject $H_{0}$ if $W_{i}>\chi_{1}^{2}$

\section{$\checkmark$ Testing of the overall significance (the likelihood ratio test)}

The overall significance test is based on the likelihood ratio between the model without the explanatory variables and the model with the explanatory variables. Indeed, the test can be expressed as follows:

$$
\left\{\begin{array}{l}
H_{0}: \operatorname{logit}(P(Y=1))=\beta_{0} \\
H_{1}: \operatorname{logit}(P(Y=1))=\beta H^{\prime}
\end{array}\right.
$$

The test ratio is defined by:

$$
\begin{array}{r}
S T=-2\left[\frac{\text { Maximum loglikelihood of the model } M_{1}}{\text { Maximum loglikelihood of the model } M_{2}}\right] \\
=-2\left[\frac{L L\left(M_{1}\right)}{L L\left(M_{2}\right)}\right]
\end{array}
$$

where:

- $\quad M_{1}$ the model defined by $\operatorname{logit}(P(Y=1))=\beta_{0}$

- Maximum loglikelihood of the model $M_{1}$ :

$$
L L\left(M_{1}\right)=\sum_{i=1}^{n} \ln \left(\frac{1}{1+e^{\beta_{0}}}\right)+y_{i} \beta_{0}
$$

- $\quad$ Maximum loglikelihood of the model $M_{2}$ :

$$
L L\left(M_{2}\right)=\sum_{i=1}^{n} \ln \left(\frac{1}{1+e^{\beta H}}\right)+y_{i} \beta H^{\prime}
$$

The ratio, under the hypothesis $H_{0}$, will follow a $\chi^{2}$ with $n$ degree of freedom. We reject $H_{0}$ if ST $>\chi_{n}^{2}$ and model $M_{2}$ is better than model $M_{1}$

\section{* The Hosmer-Lemeshow test}

The objective of this test, defined in Hosmer et al [29], is to assess the concordance between the predicted and the observed values. Indeed, the data are arranged in ascending order of the probabilities calculated by using the model, then divided into 10 groups.

The test hypotheses are:

$$
\left\{\begin{array}{c}
H_{0}: \text { the model is correct } \\
H_{1}: \text { the model is not correct }
\end{array}\right.
$$

The test statistic $(H L)$, is defined by:

$$
H L=\sum_{i=1}^{10} \frac{\left(O_{i}-n_{i} \hat{p}_{i}\right)^{2}}{n_{i} \hat{p}_{i}\left(1-\hat{p}_{i}\right)}
$$

Where $O_{i}=\sum_{j \epsilon i} y_{j}$ is the number of observed outcomes, events, in group $i, n_{i}$ is the number of observations in group $i, \hat{p}_{i}$ is the average predicted probability by the model in group $i . H L$, under the hypothesis $H_{0}$, will follow a $\chi^{2}$ with 8 degree of freedom. We reject $H_{0}$ if $H L>\chi_{8}^{2}$

* The performance of the model in the classification of the entreprise

The assessment of the performance of the model is necessary to determine the discriminatory power of the model, and to compare several models. To measure the performance of the model we will use the area under the $R O C$ curve $(A U C)$ presented previously.

A higher $A U C$ means that the discriminatory power of the model is excellent. Hosmer and al.[29] defines the general rules for classification of the models based on the $A U C$. Consequently, in our study, the model will be retained if the $A U C$ is superior or equal to 0,7, which means that the model has an acceptable discriminatory power.

\section{Determination of the Overall Score Function}

To determine the model that combines the quantitative explanatory variables $X_{j}, \mathrm{j}=1, \ldots, \mathrm{J}$, and qualitative explanatory variables $T_{i}, i=1, \ldots, 6$, we have to determine the function $f$ such that :

$$
y=f\left(X_{1}, \ldots . X_{J}, T_{1}, \ldots T_{6}\right)+\varepsilon
$$

where $f$ is a logistic probabilité

\section{- $\quad$ The pure logistic regression model.}

Let $S_{1}$ and $S_{2}$ be respectively the quantitative and qualitative score of the company $(i)$, where $S_{1}=\hat{\beta} X^{\prime}$ and $S_{2}=\hat{\tau} T^{\prime}$. The conditional probabilities $p_{1}$ and $p_{2}$ related to quantitative and qualitative data, are respectively 
$p_{1}=\frac{e^{S_{1}}}{1+e^{S_{1}}}$ and $p_{2}=\frac{e^{S_{2}}}{1+e^{S_{2}}}$.

The final score $S_{i}$ of company ( $i$ ) is defined by the weighted average of the two scores $S_{\mathrm{i} 1}$ and $S_{\mathrm{i} 2}$ and the probability $p_{i}=P\left(Y=1 / x_{i 1}, \ldots . x_{i j}, t_{i 1}, \ldots t_{i 6}\right)$ is defined by :

$$
\begin{array}{r}
p_{i}=\frac{e^{\alpha S_{\mathrm{i} 1}+(1-\alpha) S_{\mathrm{i} 2}}}{1+e^{\alpha S_{\mathrm{i} 1}+(1-\alpha) S_{\mathrm{i} 2}}}=\frac{e^{S_{i}}}{1+e^{S_{i}}} \text { where } \\
S_{i}=\alpha S_{\mathrm{i} 1}+(1-\alpha) S_{\mathrm{i} 2}
\end{array}
$$

The score function $S$ and the probability $p$ of the model can be formulated as follows:

$$
p=\frac{e^{\alpha S_{1}+(1-\alpha) S_{2}}}{1+e^{\alpha S_{1}+(1-\alpha) S_{2}}}=\frac{e^{\mathrm{S}}}{1+e^{\mathrm{S}}} \text { où } S=\alpha S_{1}+(1-\alpha) S_{2}
$$

The weighting $\alpha$ is determined according to the discriminatory power of the model. Indeed, the weighting which will be retained is those which maximizes the curve of ROC among all the values $10 \%, 20 \%, 30 \%, \ldots . ., 80 \%$ and $90 \%$.

\section{- The principal components of the logistic regression model.}

In this case, we will simultaneously treat the quantitative and qualitative variables. As a result, the probability $p_{i}=P\left(Y=1 / x_{i 1}, \ldots x_{i j}, t_{i 1}, \ldots t_{i 6}\right)$ of the company $(i)$ will be a logistic probability determined directly as a function of the eigenvectors and the cumulative variation chosen.

The formulation of the $S$ score function and the probability $p$ are determined directly by multivariate analysis of the logistic regression between the default and the principal components.

Determination of the Score Grid, and Calculation of the Probability of Default by Class.

A company ( $i$ ) is considered healthy if $p_{i} \geq \frac{1}{2}$, so:

$$
\begin{aligned}
p_{i}= & \frac{e^{S_{i}}}{1+e^{S_{i}}} \geq \frac{1}{2} \leftrightarrow e^{S_{i}} \geq \frac{1}{2}\left(1+e^{S_{i}}\right) \\
& \leftrightarrow e^{S_{i}} \geq 1 \leftrightarrow S_{i} \geq 0
\end{aligned}
$$

Consequently, the company is healthy if the score is positive.

\subsection{The Rating Grid}

The classification of healthy companies is based on the score function. Indeed, this classification gives rise to the rating grid composed of 8 rating classes.

Each company $(i)$ is classified into a rating class, the classes vary between $A$ and $H$, and are defined as follows:

Table 4. The rating grid

\begin{tabular}{|c|c|c|c|c|c|c|c|c|}
\hline Class & $A$ & $B$ & $C$ & $D$ & $E$ & $F$ & $G$ & $H$ \\
\hline Rating score & {$[86-100]$} & {$[76-86]$} & {$[65-76]$} & {$[55-65]$} & {$[46-55]$} & {$[40-46]$} & {$[30-40]$} & $<30$ \\
\hline
\end{tabular}

The rating score $S N_{i}$ of the company $(i)$ is defined by :

$$
S N_{i}=\frac{S_{i}}{\operatorname{Max}(S)} \times 100
$$

where $S_{i}$ is a score fonction of the company $(i)$.

\subsection{Calculation of the Probability of Default per Rating Class}

The probability of default of the class $K\left(P D_{K}\right)$ is defined by the probability of default of the company $(i)$ knowing that the company $(i)$ belonging to the class $K$. Consequently:

$$
=\frac{P D_{K}}{\text { Number of companies in default belonging to the class } K}
$$

To define this probability of default per rating class, we will distribute the sample of healthy and default companies as follows:

Table 5. The probability of default by class

\begin{tabular}{|c|c|c|c|c|c|c|c|c|}
\hline Class & $\mathrm{A}$ & $\mathrm{B}$ & $\mathrm{C}$ & $\mathrm{D}$ & $\mathrm{E}$ & $\mathrm{F}$ & $\mathrm{G}$ & $\mathrm{H}$ \\
\hline Rating score & {$[86-100]$} & {$[76-86[$} & {$[65-76[$} & {$[55-65[$} & {$[46-55[$} & {$[40-46[$} & {$[30-40[$} & $<30$ \\
\hline Number $\{Y=0\}$ & $n_{A 0}$ & $n_{B 0}$ & $n_{C 0}$ & $n_{D 0}$ & $n_{E 0}$ & $n_{F 0}$ & $n_{G 0}$ & $n_{H 0}$ \\
\hline Number $\{Y=1\}$ & $n_{A 1}$ & $n_{B 1}$ & $n_{C 1}$ & $n_{D 1}$ & $n_{E 1}$ & $n_{F 1}$ & $n_{G 1}$ & $n_{H 1}$ \\
\hline Total number & $n_{A}$ & $n_{B}$ & $n_{C}$ & $n_{D}$ & $n_{E}$ & $n_{F}$ & $n_{G}$ & $n_{H}$ \\
\hline $\begin{array}{c}\text { Probability of Default } \\
(P D)\end{array}$ & $\frac{n_{A 0}}{n_{A}}$ & $\frac{n_{B 0}}{n_{B}}$ & $\frac{n_{C 0}}{n_{C}}$ & $\frac{n_{D 0}}{n_{D}}$ & $\frac{n_{E 0}}{n_{E}}$ & $\frac{n_{F 0}}{n_{F}}$ & $\frac{n_{G 0}}{n_{G}}$ & $\frac{n_{H 0}}{n_{H}}$ \\
\hline
\end{tabular}




\subsubsection{Determination of Expected Credit Losses}

The expected loss is calculated by the formula (1). It depends on three components which are the $P D, L G D$ and $E A D$. The process for calculating the $P D$ was discussed in the previous paragraphs while the calculation of the $L G D$ and $E A D$ will be presented in the following paragraphs.

\subsubsection{Determination of the Loss Given Default ( $L G D)$}

The calculation of the loss given default ( $L G D$ ) consists in constructing regression models, which associated the $L G D$ with relevant factors such as the seniority of the debt, the seniority of the relationship, the date of the transfer to the banking litigation, the activity sector the company, the collection process adopted by the bank, the time required for the completion of litigation procedures in justice, the rate of coverage by the first-ranking guarantees, the economic conditions and the probability at default $(P D)$.

These variables were analyzed and used for the calibration of the model $L G D$ in numerous publications. Indeed, Chalupka and Kopecsni [19] present a case study on $L G D$ modelling of bank loans, in which the principal factors that have been identified are the period of issuance of the loan, the quality of the guarantees, the amount of the loan and the duration of the relationship with the debtor. The relationship between the default rate and the recovery rate was investigated in Altman and al ([3],[4], [6], [7]). The study of the dependence between default probabilities and recovery rates by Bade and al. [9], has shown some improvement in the $L G D$. While Gurtler et Hibbeln [27] has studied the influence of the length of the recovery process (training) on the $L G D$ level estimated.

Different regression models have been used by researchers to model loss given default $(L G D)$ as the Tobit model found in McDonald and al.[33], the Beta regression in Huang and al. [30], the inflated Beta regression in Pereira and al. [36], the censored gamma regression in Sigrist and al.[38] and [39] and a mixture of distributions into the model used, by Altman et al. [5].

In this paper, we will use the estimate provided by the Basel Accord for the loss given default ( $L G D)$, under the $I R B$ foundation approach, fixed at $45 \%{ }^{7}$. Indeed, we will ignore the guarantees associated with the credit to determine the $L G D$.

\subsubsection{Determination Exposure at Default $(E A D)$}

The exposure at default $E A D$ is defined as the sum of:

- The value accounted for in the balance sheet $\left(V C B_{0}\right)$.

- The value of the unused funding commitment, accounted for off-balance sheet $\left(V C H B_{0}\right)$ multiplied by a credit conversion factor $(C C F)$.

The credit conversion factor $(C C F)$ is defined between 0 et $1(F C C \in[0,1])$ and the mathematical formulation of the $E A D$, is given by the following relationship:

$$
E A D=V C B_{0}+C C F \times V C H B_{0}
$$

The calculation of the exposure at default $(E A D)$ will be done in two different ways. The first, consists in modelling the credit conversion factor $(C C F)$ by using regression models that associated the $C C F$ with pertinent factors, whereas the second, consists in modelling directly the exposure at default $(E A D)$.

The models used to model the credit conversion factor $(C C F)$ such as the ordinary least squares $(O L S)$, the Tobit model, the fractional response regression and the utilization change model, are detailed in Brown [17], Bellotti and al. [14] and Bijak and al. [15]. While the models used for the direct modelling of the $E A D$ as a zero-adjusted gamma model and others, are detailed in E.N.C. Tong and al.[22].

In this paper, we will use the estimate provided by the Basel Accord for credit conversion factor $(C C F)$ at the paragraph level 366. Indeed, under the $I R B$ foundation approach, the $C C F$ is fixed at $75 \%$. The exposure at default $(E A D)$ of the line of credit is determined as follows :

$$
\begin{gathered}
E A D=V C B_{0}+F C C \times V C H B_{0} \\
E A D=V C B_{0}+75 \% \times V C H B_{0} \\
E A D=V C B_{0}+75 \% \times\left(M_{e f a}-V C B_{0}\right) \\
E A D=25 \% V C B_{0}+75 \% \times M_{e f a}
\end{gathered}
$$

where $M_{e f a}$ the amount of the financing authorization granted by the bank to the customer.

\section{Empirical Results}

\subsection{Description of the Database}

In this study, we used a database of small and medium enterprises (SMEs) of a Moroccan bank composed of 1447 enterprises. For the definition of a $S M E$ we have based on the definition of the Central Bank which considers that an enterprise is an $S M E$ if it realizes a turnover between 10 and 175 million $M A D$. In terms of default, the portfolio structure is as follows:

Table 6. Default Portfolio Structure

\begin{tabular}{|c|c|c|}
\hline & Number & percentage \\
\hline Healthy Enterprises & 1333 & $92.12 \%$ \\
\hline Enterprises in default & 114 & $7.88 \%$ \\
\hline Total & 1447 & $100 \%$ \\
\hline
\end{tabular}




\subsection{Choice of Explanatory Variables}

\subsubsection{Choice of Quantitative Variables}

The univariate analysis of the quantitative variables has permitted to determine the quantitative variables which explain the failure. The choice of quantitative variables, is based on the Wald test and the discriminatory power (power stat), determined from the $A U C$ and the $A R$. Indeed, the Wald test and the discriminatory power made have permitted to determine the seven explanatory variables follows:

Table 7. univariate analysis and choice of quantitative variables

\begin{tabular}{|c|c|c|c|c|c|}
\hline Title & variable & Khi $^{2}$ (Wald) & $p v=\operatorname{Pr}(x>$ Wald $)$ & AUC & AR \\
\hline Profit growth & $X_{1}=\mathrm{V}_{3}$ & 4,782 & 0,029 & $61 \%$ & $22 \%$ \\
\hline$\frac{\text { Net Profit }}{\text { Equity }}$ & $X_{2}=\mathrm{V}_{5}$ & 9,427 & 0,002 & $30 \%$ \\
\hline $\begin{array}{c}\text { Financial expenses } \\
\text { Sales/turnove (ST) }\end{array}$ & $X_{3}=\mathrm{V}_{7}$ & 23,912 & $<0,0001$ & $38,4 \%$ \\
\hline$\frac{\text { Net Debt }}{\text { Equity }}$ & $X_{4}=\mathrm{V}_{9}$ & 23,683 & $<0,0001$ & $69 \%$ & $38 \%$ \\
\hline Liquidity & $X_{5}=\mathrm{V}_{10}$ & 6,136 & 0,013 & $63.3 \%$ & $26.6 \%$ \\
\hline Equity & $X_{6}=\mathrm{V}_{12}$ & 6,590 & 0,010 & $28 \%$ \\
\hline Satal Assets & $X_{7}=\mathrm{V}_{13}$ & 10,289 & 0,001 & $65 \%$ & $30 \%$ \\
\hline
\end{tabular}

For the variables listed in the table 7 , the Wald's test shows that the selected variables are significant because the p-value $(p v)$ is inferior to 0,05 with a satisfactory discriminatory power because the $A U C$ is superior to 0,6 and the $A R$ is superior to 0,2 .

The correlation between the selected quantitative variables is presented as follows:

Table 8. The correlation matrix of quantitative variables.

\begin{tabular}{|c|c|c|c|c|c|c|c|}
\hline Variables & $\mathrm{X}_{1}$ & $\mathrm{X}_{2}$ & $\mathrm{X}_{3}$ & $\mathrm{X}_{4}$ & $\mathrm{X}_{5}$ & $\mathrm{X}_{6}$ & $\mathrm{X}_{7}$ \\
\hline $\mathrm{X}_{1}$ & 1,000 & 0,128 & 0,076 & 0,060 & 0,067 & 0,109 & 0,008 \\
\hline $\mathrm{X}_{2}$ & 0,128 & 1,000 & $-0,021$ & 0,069 & 0,087 & 0,213 & $-0,084$ \\
\hline $\mathrm{X}_{3}$ & 0,076 & $-0,021$ & 1,000 & 0,415 & 0,195 & 0,085 & 0,440 \\
\hline $\mathrm{X}_{4}$ & 0,060 & 0,069 & 0,415 & 1,000 & 0,297 & 0,357 & 0,358 \\
\hline $\mathrm{X}_{5}$ & 0,067 & 0,087 & 0,195 & 0,297 & 1,000 & 0,371 & $-0,027$ \\
\hline $\mathrm{X}_{6}$ & 0,109 & 0,213 & 0,085 & 0,357 & 0,371 & 1,000 & $-0,159$ \\
\hline $\mathrm{X}_{7}$ & 0,008 & $-0,084$ & 0,440 & 0,358 & $-0,027$ & $-0,159$ & 1,000 \\
\hline
\end{tabular}

The previous matrix shows that the variables are not strongly correlated because the correlation coefficients do not exceed 0,5 .

\subsubsection{Choice of Qualitative Variables}

Similarly, for the qualitative variables, the choice is based on Wald's test and on the discriminatory power (power stat). The following table summarizes the results.

Table 9. univariate analysis and choice of qualitative variables.

\begin{tabular}{|c|c|l|l|l|l|l|}
\hline$\left(q_{m}\right)$ & theme & qualitative variables & Khi $^{2}($ Wald $)$ & $p v=P(x>$ Wald $)$ & AUC & AR \\
\hline$q_{1}$ & $T_{1}$ & Sector fault rate & 7,378 & 0,007 & $61,5 \%$ & $23 \%$ \\
\hline$q_{6}$ & $T_{2}$ & International Competition & 3,875 & 0,049 & $60,5 \%$ & $21 \%$ \\
\hline$q_{12}$ & $T_{4}$ & Seniority of the principal operational staff & 3,840 & 0,050 & $60 \%$ & $20 \%$ \\
\hline$q_{17}$ & $T_{5}$ & $\begin{array}{l}\text { Number of payment incidents in the last } 12 \\
\text { months }\end{array}$ & 141,290 & $<0,0001$ & $79,9 \%$ & $59,8 \%$ \\
\hline$q_{19}$ & $T_{6}$ & Number of banks related to the company & 11,227 & 0,001 & $65,4 \%$ & $30,8 \%$ \\
\hline
\end{tabular}

For each theme, we found that only one variable is significant except for theme $T_{3}$ where the variables are not significant. Consequently, the modelling of the themes is equivalent to the modelling of the selected variables. 
As with the quantitative variables, the Wald's test shows that the selected variables are significant because the p-value $(p v)$ is inferior to 0,05 . For the discriminatory power, the variables have a satisfying discriminatory power because the $A U C$ is superior to 0,6 and the $A R$ is superior to 0,2 .

The correlation between the chosen qualitative variables is presented as follows:

Table 10. The correlation matrix of quantitative variables.

\begin{tabular}{|c|c|c|c|c|c|}
\hline Variables & $T_{1}$ & $T_{2}$ & $T_{4}$ & $T_{5}$ & $T_{6}$ \\
\hline$T_{1}$ & 1,000 & 0,072 & $-0,079$ & $-0,012$ & 0,053 \\
\hline$T_{2}$ & 0,072 & 1,000 & 0,029 & $-0,039$ & 0,078 \\
\hline$T_{4}$ & $-0,079$ & 0,029 & 1,000 & $-0,035$ & $-0,040$ \\
\hline$T_{5}$ & $-0,012$ & $-0,039$ & $-0,035$ & 1,000 & 0,043 \\
\hline$T_{6}$ & 0,053 & 0,078 & $-0,040$ & 0,043 & 1,000 \\
\hline
\end{tabular}

The previous matrix shows that the variables are not strongly correlated because the correlation coefficients do not exceed 0,5 .

\subsection{Calculation of the Expected Loss from the Rating Model based on Pure Logistic Regression.}

We have previously presented the process of construction of the rating tool. Indeed, we will determine in this paragraph the rating grid and the probability of default by class by using pure logistic regression.

\subsubsection{Multivariate Analysis and Determination of the Score Function.}

\subsubsection{Multivariate Analysis and Determination of the Score Function of Quantitative Variables.}

\section{- Parameter estimation and testing of significance.}

The parameters estimation and the tests of significance of the coefficients are presented as follows:

* The parameters estimations and the Wald's test.

The maximization of the likelihood function is done by the Newton-Raphson algorithm. The results of the estimation of the parameters and Wald's significance test are presented in the following table:

Table 11. The parameters estimations and the Wald's test

\begin{tabular}{|c|c|c|c|c|}
\hline & $\beta_{\mathrm{i}}$ & Standard deviation & Khi $^{2}$ (Wald) & $p v=P(x>$ Wald $)$ \\
\hline Cte & $\beta_{0}=0,706$ & 0,356 & 3,942 & 0,047 \\
\hline $\mathrm{X}_{1}$ & $\beta_{1}=0,004$ & 0,003 & 4,050 & 0,044 \\
\hline $\mathrm{X}_{2}$ & $\beta_{2}=0,009$ & 0,004 & 5,223 & 0,022 \\
\hline $\mathrm{X}_{3}$ & $\beta_{3}=0,009$ & 0,003 & 9,104 & 0,003 \\
\hline $\mathrm{X}_{4}$ & $\beta_{4}=0,007$ & 0,003 & 4,431 & 0,035 \\
\hline $\mathrm{X}_{5}$ & $\beta_{5}=0,002$ & 0,001 & 3,896 & 0,048 \\
\hline $\mathrm{X}_{6}$ & $\beta_{6}=0,003$ & 0,001 & 4,355 & 0,037 \\
\hline $\mathrm{X}_{7}$ & $\beta_{7}=0,003$ & 0,002 & 4,225 & 0,040 \\
\hline
\end{tabular}

Wald's test confirms the significance of the coefficients $\beta_{i}$ because the p-value ( $p v$ ) of all variables is inferior to 0,05 .

* The testing of the overall significance (the likelihood ratio test)

The likelihood ratio test shows that the value of the $S T$ statistic, previously defined, is equal to 46,883 , this value is superior to 14,067 ( $\chi^{2}$ of degree 7 at the 0,05 threshold). Consequently, we reject $H_{0}$ and the variables are totally significant and determine a better model.

\section{- Hosmer-Lemeshow test and the assessment of the performance of the model.}

* The Hosmer-Lemeshow test

The Hosmer-Lemeshow test shows that the model fits with the sample data. Indeed, the $H L$ statistic is equal to 4,42 with a p-value equal to 0,817 , superior to the threshold of 0,05 .

* The assessment of the performance of the model

The $R O C$ curve shows that the model offers an acceptable classification of companies because the $A U C$ is equal to 0,705 . 


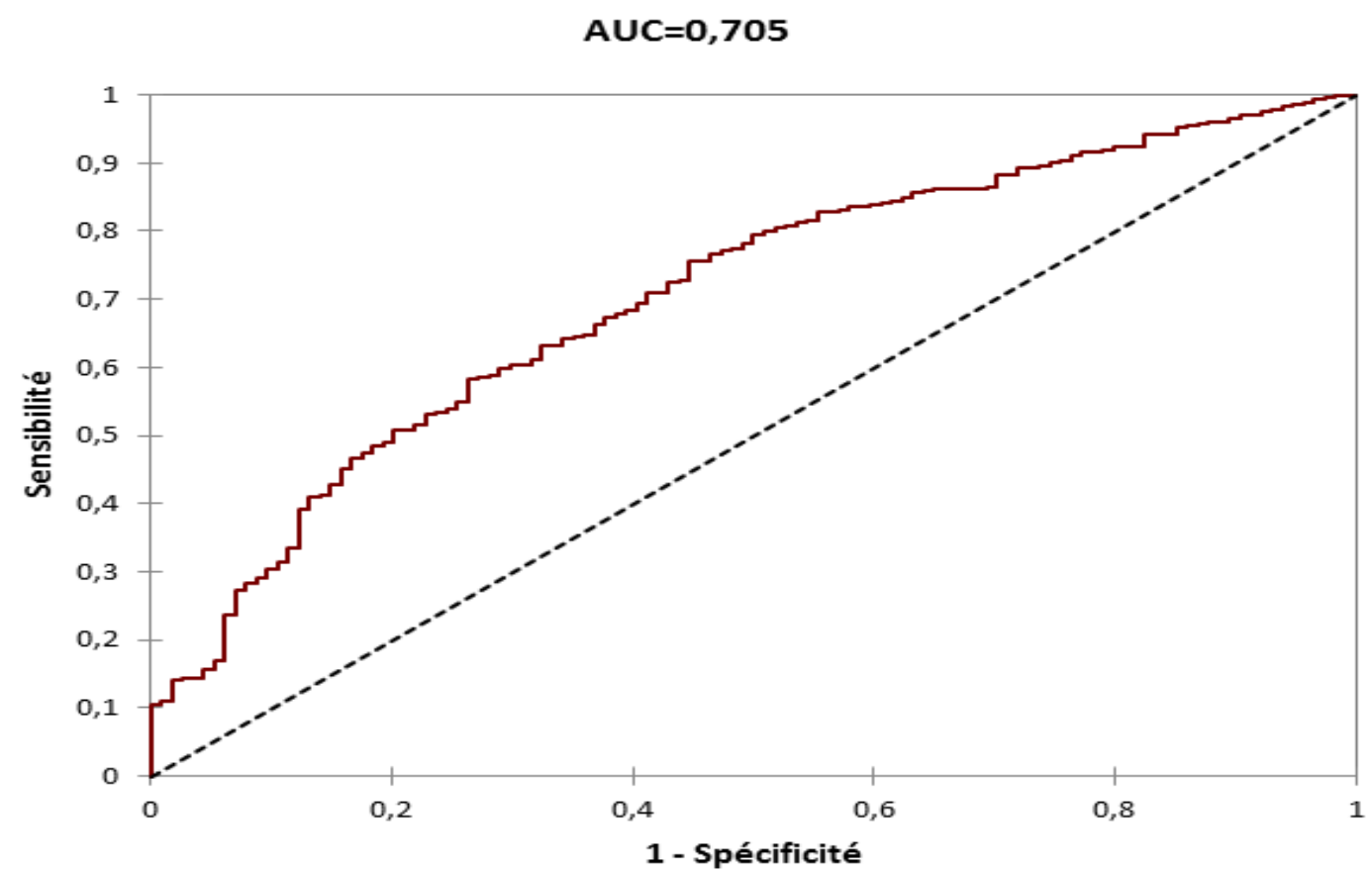

Figure 3. The AUC of quantitatives variables

\section{- Determination of the score function.}

For each company $(i)$ the score of company $S_{1}(i)$ is written as follows:

$$
S_{1}(i)=\beta_{0}+\beta_{1} X_{i, 1}+\beta_{2} X_{i, 2}+\beta_{3} X_{i, 3}+\beta_{4} X_{i, 4}+\beta_{5} X_{i, 5}+\beta_{6} X_{i, 6}+\beta_{7} X_{i, 7}
$$

As a result, the variable $Y_{i}$ can be estimated by the probability:

$$
\begin{gathered}
p_{1 i}=\frac{e^{\beta_{0}+\beta_{1} X_{i, 1}+\beta_{2} X_{i, 2}+\beta_{3} X_{i, 3}+\beta_{4} X_{i, 4}+\beta_{5} X_{i, 5}+\beta_{6} X_{i, 6}+\beta_{7} X_{i, 7}}}{1+e^{\beta_{0}+\beta_{1} X_{i, 1}+\beta_{2} X_{i, 2}+\beta_{3} X_{i, 3}+\beta_{4} X_{i, 4}+\beta_{5} X_{i, 5}+\beta_{6} X_{i, 6}+\beta_{7} X_{i, 7}}} \\
p_{1 i}=\frac{e^{0,706+0,04 X_{i, 1}+0,09 X_{i, 2}+0,09 X_{i, 3}+0,07 X_{i, 4}+0,02 X_{i, 5}+0,03 X_{i, 6}+0,03 X_{i, 7}}}{1+e^{0,706+0,04 X_{i, 1}+0,09 X_{i, 2}+0,09 X_{i, 3}+0,07 X_{i, 4}+0,02 X_{i, 5}+0,03 X_{i, 6}+0,03 X_{i, 7}}}
\end{gathered}
$$

Hence, the variable $Y$ can be estimated by the probability:

$$
p_{1}=\frac{e^{0,706+0,04 X_{1}+0,09 X_{2}+0,09 X_{3}+0,07 X_{4}+0,02 X_{5}+0,03 X_{6}+0,03 X_{7}}}{1+e^{0,706+0,04 X_{1}+0,09 X_{2}+0,09 X_{3}+0,07 X_{4}+0,02 X_{5}+0,03 X_{6}+0,03 X_{7}}}
$$

3.3.1.2. Multivariate Analysis and Determination of the Score Function of Qualitative Variables.

\section{- Parameter estimation and testing of significance.}

The parameters estimation and the tests of significance of the coefficients are presented as follows:

* The parameters estimations and the Wald's test.

The maximization of the likelihood function is done by the Newton-Raphson algorithm. The results of the estimation of the parameters and Wald's test are presented as follows:

Table 12. The estimation of the parameters and the Wald's test

\begin{tabular}{|c|c|c|c|c|}
\hline & $\tau_{\mathrm{i}}$ & Standard deviation & $\mathrm{Khi}^{2}(\mathrm{Wald})$ & $p v=P(x>$ Wald $)$ \\
\hline Constant & $\tau_{0}=-5,650$ & 0,755 & 55,954 & $<0,0001$ \\
\hline$T_{1}$ & $\tau_{1}=0,009$ & 0,003 & 9,195 & 0,002 \\
\hline$T_{2}$ & $\tau_{2}=0,007$ & 0,004 & 4,221 & 0,040 \\
\hline$T_{4}$ & $\tau_{3}=0,012$ & 0,005 & 7,685 & 0,006 \\
\hline$T_{5}$ & $\tau_{4}=0,083$ & 0,007 & 138,743 & $<0,0001$ \\
\hline$T_{6}$ & $\tau_{5}=0,012$ & 0,005 & 6,642 & 0,010 \\
\hline
\end{tabular}

Wald's test confirms the significance of the coefficients $\tau_{i}$ because the p-value ( $\left.p v\right)$ of all variables is inferior to 0,05 .

* The testing of the overall significance (the likelihood ratio test) 
The likelihood ratio test shows that the value of the $S T$ statistic, previously defined, is equal to 178,364 , this value is superior to 14,067 ( $\chi^{2}$ of degree 7 at the 0,05 threshold). Consequently, we reject $H_{0}$ and the variables are totally significant and determine a better model.

\section{- Hosmer-Lemeshow test and the assessment of the performance of the model.}

* The Hosmer-Lemeshow test

The Hosmer-Lemeshow test shows that the model fits with the sample data. Indeed, the $H L$ statistic is equal to 12,265 with a p-value equal to 0,092 , superior to the threshold of 0,05 .

* The assessment of the performance of the model

The $R O C$ curve shows that the model offers an acceptable classification of companies because the $A U C$ is equal to 0,784 .

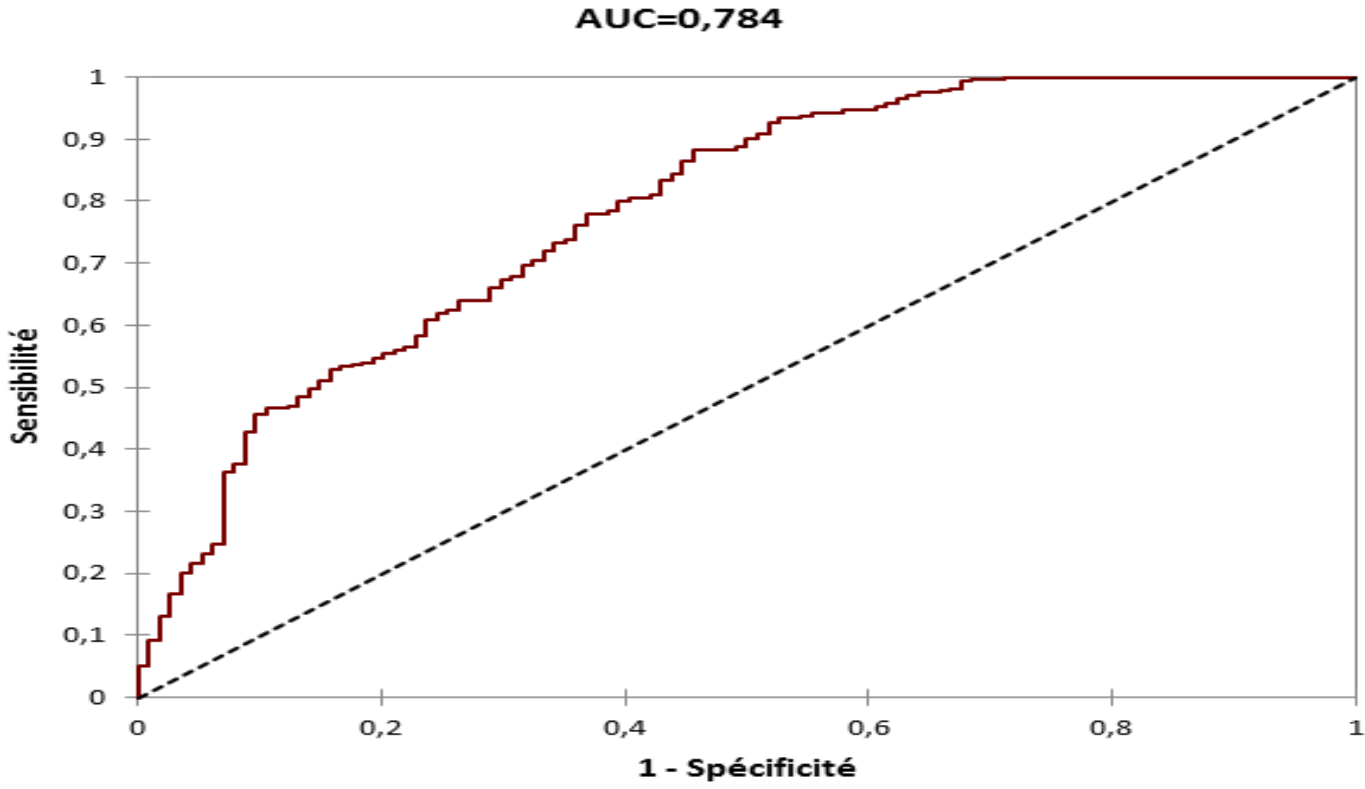

Figure 4. The AUC of quanlitatives variables

\section{- Determination of the score function.}

For each company $(i)$ the score of company $S_{2}(i)$ is written as follows:

$$
S_{2}(i)=\tau_{0}+\tau_{1} T_{i, 1}+\tau_{2} T_{i, 2}+\tau_{3} T_{i, 4}+\tau_{4} T_{i, 5}+\tau_{5} T_{i, 6}
$$

As a result, the variable $Y_{i}$ can be estimated by the probability:

$$
\begin{gathered}
p_{2 i}=\frac{e^{\tau_{0}+\tau_{1} T_{i, 1}+\tau_{2} T_{i, 2}+\tau_{3} T_{i, 4}+\tau_{4} T_{i, 5}+\tau_{5} T_{i, 6}}}{1+e^{\tau_{0}+\tau_{1} T_{i, 1}+\tau_{2} T_{i, 2}+\tau_{3} T_{i, 4}+\tau_{4} T_{i, 5}+\tau_{5} T_{i, 6}}} \\
p_{2 i}=\frac{e^{-5,650+0,009 * T_{i, 1}+0,007 * T_{i, 2}+0,012 * T_{i, 4}+0,083 * T_{i, 5}+0,012 * T_{i, 6}}}{1+e^{-5,650+0,009 * T_{i, 1}+0,007 * T_{i, 2}+0,012 * T_{i, 4}+0,083 * T_{i, 5}+0,012 * T_{i, 6}}}
\end{gathered}
$$

Hence, the variable $Y$ can be estimated by the probability:

$$
p_{2}=\frac{e^{-5,650+0,009 * T_{1}+0,007 * T_{2}+0,012 * T_{4}+0,083 * T_{5}+0,012 * T_{6}}}{1+e^{-5,650+0,009 * T_{1}+0,007 * T_{2}+0,012 * T_{4}+0,083 * T_{5}+0,012 * T_{6}}}
$$

\subsubsection{The Function of Overall Score and the Construction of the Rating Grid.}

\subsubsection{Determination of the Function of Overall Score.}

The combination of the quantitative and qualitative score to determine the overall score is based on the maximization of the discriminatory power of the model. Therefore, we will retain the combination $\alpha S_{1}+(1-\alpha) S_{2}$ that maximizes the $A U C$. To achieve this, we have varied $\alpha$ and we calculated the $A U C$. The results are presented below: 
Table 13. Variation in the weighting $(\alpha)$ and the $A U C$

\begin{tabular}{|c|c|c|c|c|c|c|c|c|c|}
\hline$\alpha$ & $10 \%$ & $20 \%$ & $30 \%$ & $40 \%$ & $50 \%$ & $60 \%$ & $70 \%$ & $80 \%$ & $90 \%$ \\
\hline$A U C$ & 0,79 & 0,795 & 0,799 & 0,8016 & 0,80338 & 0,80226 & 0,798 & 0,78 & 0,744 \\
\hline
\end{tabular}

The value of $(\alpha)$ equal to $50 \%$ is the one that maximizes the $A U C$. Therefore, we have retained the model that gives the same weight to the quantitative and qualitative score.

\subsubsection{The Construction of the Rating Grid.}

The score grid and the rating classes defined per score and the distribution of the enterprises of the sample per the rating classes, are as follows:

Table 14. The score grid, the rating classes and the distribution of the enterprises

\begin{tabular}{|c|c|c|c|}
\hline \multirow{2}{*}{ Rating classes } & \multirow{2}{*}{ Score } & \multicolumn{2}{|c|}{ Distribution of the companies } \\
\cline { 2 - 4 } & & 19 & $1,3 \%$ \\
\hline A & {$[86-100]$} & 279 & $19,3 \%$ \\
\hline B & {$[76-86[$} & 460 & $31,8 \%$ \\
\hline C & {$[65-76[$} & 372 & $25,7 \%$ \\
\hline D & {$[55-65[$} & 164 & $11,3 \%$ \\
\hline E & {$[46-55[$} & 55 & $3,8 \%$ \\
\hline F & {$[40-46[$} & 50 & $3,5 \%$ \\
\hline G & {$[30-40[$} & 48 & $3,3 \%$ \\
\hline H & $<30$ & & \\
\hline
\end{tabular}

The distribution of the portfolio is presented in the following graph:

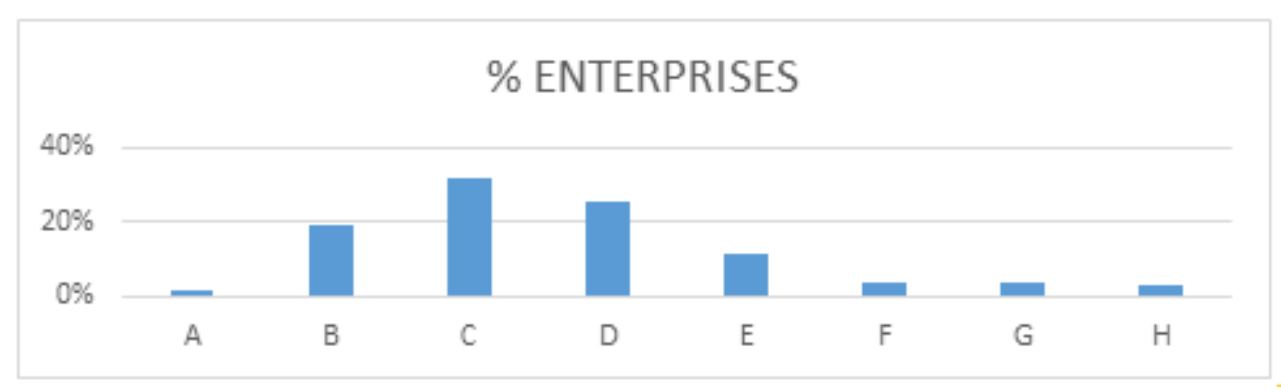

Figure 5. The distribution of the portfolio enterprises

3.3.3. Determination of the Probability of Default per Class and Calculation of the Expected Credit Loss $(E C L)$.

3.3.3.1. Determination of the Probability of Default per Rating Class.

For this first model, the probability of default is determined according to the approach detailed above. Therefore, the $P D$ per rating class is presented as follows:

Table 15. Model 1, probability of default by rating class

\begin{tabular}{|c|c|c|c|}
\hline Rating class & Number of healthy enterprises & Number of enterprises in default & PD \\
\hline A & 19 & 0 & $0,03 \%$ \\
\hline B & 276 & 3 & $1,08 \%$ \\
\hline C & 445 & 15 & $3,26 \%$ \\
\hline D & 345 & 27 & $7,26 \%$ \\
\hline E & 150 & 14 & $8,54 \%$ \\
\hline F & 50 & 5 & $9,09 \%$ \\
\hline G & 36 & 14 & $28,00 \%$ \\
\hline H & 12 & 36 & $75,00 \%$ \\
\hline Total & 1333 & 114 & \\
\hline
\end{tabular}

\subsubsection{Calculation of Expected Credit Loss $(E C L)$.}

The portfolio studied represents a use of outstanding credits $\left(V C B_{0}\right)$ of 7.496,370 Million $M A D$ distributed per rating class as follows: 
Table 16. Distribution of the $V C B_{0}$ per rating class (in Million $M A D$ )

\begin{tabular}{|c|c|c|}
\hline Rating Class & $V C B_{0}$ (amount) & $0,6 \%$ \\
\hline A & 45 & $8,0 \%$ \\
\hline B & 598 & $18,4 \%$ \\
\hline C & 1379 & $33,9 \%$ \\
\hline D & 2543 & $19,6 \%$ \\
\hline E & 1471 & $6,4 \%$ \\
\hline F & 483 & $7,6 \%$ \\
\hline G & 572 & $5,4 \%$ \\
\hline H & 406 & $100,0 \%$ \\
\hline Total & 7496 & \multicolumn{2}{|c|}{} \\
\hline
\end{tabular}

The amount of the expected loss per rating class is determined by the formula (1). As a result, for a loss given default $(L G D)$ equal to $45 \%$ and a $F C C$ equal to $75 \%$, the total amount of the expected loss $\left(E L_{M}\right)$ is distributed per rating class as follows :

Table 17. Distribution of expected loss amount (in Million $M A D$ )

\begin{tabular}{|c|c|c|c|c|c|c|}
\hline Rating class & $V C B_{0}$ & $M_{e f a}$ & $P D$ & $L G D$ & $E A D$ & $E L_{M}$ \\
\hline A & 45 & 50 & $0,03 \%$ & $45 \%$ & 54 & 0,01 \\
\hline B & 598 & 748 & $1,08 \%$ & $45 \%$ & 648 & 3,15 \\
\hline C & 1379 & 1622 & $3,26 \%$ & $45 \%$ & 1494 & 21,92 \\
\hline $\mathrm{D}$ & 2543 & 2992 & $7,26 \%$ & $45 \%$ & 2803 & 91,58 \\
\hline $\mathrm{E}$ & 1471 & 1961 & $8,54 \%$ & $45 \%$ & 1990 & 76,48 \\
\hline $\mathrm{F}$ & 483 & 537 & $9,09 \%$ & $45 \%$ & 574 & 23,46 \\
\hline G & 572 & 572 & $28,00 \%$ & $45 \%$ & 572 & 72,07 \\
\hline $\mathrm{H}$ & 406 & 406 & $75,00 \%$ & $45 \%$ & 406 & 137,03 \\
\hline Total & 7496 & 8888 & & & 8540 & 425,69 \\
\hline
\end{tabular}

\subsection{Calculation of the Expected Loss from the Rating Models based on Logistic Regression on Principal Components.}

\subsubsection{Determination of Eigenvectors.}

3.4.1.1. Determination of the Eigenvalues and the Cumulative Variation $(C V)$.

The principal components analysis makes it possible to determine the eigenvalues as well as the cumulative variation. The results are summarized below:

Table 18. The eigenvalues and variation

\begin{tabular}{|c|c|c|c|c|c|c|c|c|c|c|c|c|}
\hline & $F_{1}$ & $F_{2}$ & $F_{3}$ & $F_{4}$ & $F_{5}$ & $F_{6}$ & $F_{7}$ & $F_{8}$ & $F_{9}$ & $F_{10}$ & $F_{11}$ & $F_{12}$ \\
\hline Eigenvalues & 2,16 & 1,68 & 1,12 & 1,06 & 0,98 & 0,93 & 0,89 & 0,87 & 0,77 & 0,63 & 0,52 & 0,40 \\
\hline Variation (\%) & 18,02 & 13,96 & 9,33 & 8,82 & 8,19 & 7,76 & 7,42 & 7,23 & 6,42 & 5,22 & 4,30 & 3,33 \\
\hline Cumulative variation & 18,02 & 31,98 & 41,31 & 50,13 & 58,32 & 66,08 & 73,50 & 80,73 & 87,15 & 92,37 & 96,67 & 100,00 \\
\hline
\end{tabular}

The vectors from $F_{1}$ to $F_{7}$ offer a cumulative variation superior to 70\%, the vectors from $F_{1}$ to $F_{8}$ offer a cumulative variation superior to $80 \%$ and the vectors from $F_{1}$ to $F_{10}$ offer a cumulative variation superior to $90 \%$. Therefore, we will use them to calculate the expected loss corresponding to the cumulative variation of $70 \%, 80 \%$ and $90 \%$.

\subsubsection{Determination of Eigenvectors.}

The eigenvectors $F_{\mathrm{i}}$ are determined by the combination of quantitative and qualitative explanatory variables as follows: 
Table 19. The eigenvectors

\begin{tabular}{|c|c|c|c|c|c|c|c|c|c|c|c|c|}
\hline & $F_{1}$ & $F_{2}$ & $F_{3}$ & $F_{4}$ & $F_{5}$ & $F_{6}$ & $F_{7}$ & $F_{8}$ & $F_{9}$ & $F_{10}$ & $F_{11}$ & $F_{12}$ \\
\hline$T_{1}$ & 0,160 & $-0,167$ & 0,362 & 0,512 & $-0,129$ & $-0,552$ & $-0,010$ & $-0,016$ & $-0,454$ & 0,148 & 0,037 & 0,056 \\
\hline$T_{2}$ & 0,064 & 0,130 & 0,676 & 0,051 & 0,166 & 0,155 & $-0,525$ & 0,292 & 0,293 & $-0,142$ & $-0,003$ & 0,012 \\
\hline$T_{4}$ & $-0,092$ & 0,367 & 0,021 & $-0,246$ & $-0,005$ & $-0,393$ & 0,340 & 0,692 & 0,078 & 0,193 & 0,036 & $-0,055$ \\
\hline$T_{5}$ & 0,166 & $-0,097$ & $-0,369$ & $-0,177$ & 0,656 & $-0,287$ & $-0,441$ & 0,119 & $-0,248$ & $-0,016$ & $-0,112$ & $-0,004$ \\
\hline$T_{6}$ & 0,227 & $-0,042$ & 0,295 & 0,057 & 0,561 & 0,369 & 0,581 & 0,030 & $-0,229$ & $-0,006$ & $-0,100$ & 0,070 \\
\hline $\mathrm{X}_{1}$ & 0,119 & 0,152 & $-0,373$ & 0,526 & $-0,171$ & 0,438 & $-0,145$ & 0,493 & $-0,228$ & $-0,029$ & $-0,085$ & 0,034 \\
\hline $\mathrm{X}_{2}$ & 0,102 & 0,327 & $-0,183$ & 0,526 & 0,309 & $-0,194$ & 0,093 & $-0,237$ & 0,582 & 0,188 & 0,011 & 0,029 \\
\hline $\mathrm{X}_{3}$ & 0,495 & $-0,223$ & $-0,073$ & $-0,098$ & $-0,032$ & 0,088 & $-0,014$ & 0,103 & 0,117 & 0,191 & 0,787 & 0,036 \\
\hline $\mathrm{X}_{4}$ & 0,526 & 0,060 & $-0,054$ & $-0,148$ & $-0,217$ & $-0,158$ & 0,076 & 0,008 & 0,138 & $-0,366$ & $-0,288$ & 0,617 \\
\hline $\mathrm{X}_{5}$ & 0,333 & 0,371 & 0,083 & $-0,233$ & $-0,146$ & 0,167 & $-0,178$ & $-0,216$ & $-0,170$ & 0,681 & $-0,263$ & $-0,033$ \\
\hline $\mathrm{X}_{6}$ & 0,297 & 0,520 & 0,008 & $-0,031$ & $-0,049$ & $-0,078$ & 0,030 & $-0,194$ & $-0,213$ & $-0,500$ & 0,166 & $-0,520$ \\
\hline $\mathrm{X}_{7}$ & 0,371 & $-0,467$ & $-0,020$ & 0,017 & $-0,121$ & $-0,052$ & 0,089 & 0,162 & 0,301 & 0,032 & $-0,410$ & $-0,577$ \\
\hline
\end{tabular}

3.4.2. Univariate Analysis of Variables $\boldsymbol{F}_{\mathbf{i}}$ and Study of the Correlation between $\boldsymbol{F}_{\mathbf{i}}$ and $\boldsymbol{Y}$.

The objective of the univariate analysis is to verify if the correlation between the failure and the main components is maintained as in the case of the initial variables, or the transformation generates a loss of information. The results of this analysis are as follows:

Table 20. Univariate analysis of variables of the eigenvectors

\begin{tabular}{|c|c|c|c|c|}
\hline variable & $\mathrm{Khi}^{2}$ (Wald) & $p v=\operatorname{Pr}(x>$ Wald $)$ & $A U C$ & $A R$ \\
\hline$F_{1}$ & 61,738 & $<0,0001$ & $72,2 \%$ & $44,4 \%$ \\
\hline$F_{2}$ & 0,015 & 0,901 & $50 \%$ & $0 \%$ \\
\hline$F_{3}$ & 15,082 & 0,000 & $58,6 \%$ & $17,2 \%$ \\
\hline$F_{4}$ & 0,278 & 0,598 & $51,5 \%$ & $3 \%$ \\
\hline$F_{5}$ & 88,887 & $<0,0001$ & $69,2 \%$ & $38,4 \%$ \\
\hline$F_{6}$ & 26,163 & $<0,0001$ & $62,8 \% \%$ & $25,6 \%$ \\
\hline$F_{7}$ & 25,725 & $<0,0001$ & $62,5 \%$ & $25 \%$ \\
\hline$F_{8}$ & 19,627 & $<0,0001$ & $62,2 \%$ & $24,4 \%$ \\
\hline$F_{9}$ & 8,036 & 0,005 & $55,8 \%$ & $11,6 \%$ \\
\hline$F_{10}$ & 0,305 & 0,581 & $52,3 \%$ & $4,6 \%$ \\
\hline$F_{11}$ & 1,938 & 0,164 & $54,3 \%$ & $8,6 \%$ \\
\hline$F_{12}$ & 0,338 & 0,561 & 50,7 & $1,4 \%$ \\
\hline
\end{tabular}

The Table 20 shows that the correlation between $Y$ and the $F_{i}$ is lost for some eigenvectors by transforming the initial variables into the principal components. However, in the modelling we will retain all components including those whose significance is not justified.

\subsubsection{Multivariate Analysis and Determination of the Score Function}

\subsubsection{Multivariate Analysis per Level of Cumulative Variation (CV)}

Multivariate analysis will be done for the three levels of cumulative variation, respectively $70 \%$, $80 \%$ and $90 \%$. The results of this analysis are as follows: 
Table 21. Multivariate analysis per level of cumulative variation

\begin{tabular}{|c|c|c|c|c|c|c|c|c|c|c|c|c|}
\hline & \multicolumn{4}{|c|}{ Model 2: $C V$ is equal to $70 \%$} & \multicolumn{4}{|c|}{ Model 3: $C V$ is equal to $80 \%$} & \multicolumn{4}{|c|}{ Model $4: C V$ is equal to $90 \%$} \\
\hline & $\begin{array}{c}\text { Valu } \\
\mathrm{e}\end{array}$ & $\begin{array}{l}\text { ST. } \\
\text { Dev. }\end{array}$ & $\begin{array}{l}\text { Khi }^{2} \\
\text { Wald }\end{array}$ & $\begin{array}{l}P v=P(x \\
\left.>K h i^{2}\right)\end{array}$ & Value & $\begin{array}{l}\text { ST. } \\
\text { Dev. }\end{array}$ & $\begin{array}{l}\text { Khi }^{2} \\
\text { Wald }\end{array}$ & $\begin{array}{l}P v=P(x \\
\left.>K h i^{2}\right)\end{array}$ & $\begin{array}{c}\text { Valu } \\
\text { e }\end{array}$ & $\begin{array}{l}\text { ST. } \\
\text { Dev. }\end{array}$ & $\begin{array}{l}\text { Khi }^{2} \\
\text { Wald }\end{array}$ & $\begin{array}{l}P v=P(x \\
\left.>K h i^{2}\right)\end{array}$ \\
\hline Cte & 3,02 & 0,14 & $\begin{array}{c}468, \\
74\end{array}$ & $<0,0001$ & 3,08 & 0,14 & 457,69 & $<0,0001$ & 3,10 & 0,15 & $\begin{array}{c}451,0 \\
7\end{array}$ & 3,10 \\
\hline$F_{1}$ & 0,52 & 0,08 & $\begin{array}{c}44,1 \\
4\end{array}$ & $<0,0001$ & 0,53 & 0,08 & 44,61 & $<0,0001$ & 0,54 & 0,08 & 45,11 & 0,54 \\
\hline$F_{2}$ & 0,04 & 0,09 & 0,17 & 0,682 & 0,02 & 0,09 & 0,05 & 0,820 & 0,04 & 0,09 & 0,19 & 0,04 \\
\hline$F_{3}$ & $-0,14$ & 0,10 & 2,14 & 0,143 & $-0,14$ & 0,10 & 2,13 & 0,145 & $-0,13$ & 0,10 & 1,70 & $-0,13$ \\
\hline$F_{4}$ & 0,01 & 0,10 & 0,00 & 0,959 & 0,02 & 0,10 & 0,04 & 0,832 & 0,03 & 0,10 & 0,11 & 0,03 \\
\hline$F_{5}$ & 0,66 & 0,10 & $\begin{array}{c}46,5 \\
1\end{array}$ & $<0,0001$ & 0,65 & 0,10 & 43,27 & $<0,0001$ & 0,64 & 0,10 & 41,82 & 0,64 \\
\hline$F_{6}$ & $-0,37$ & 0,11 & $\begin{array}{c}10,8 \\
0\end{array}$ & 0,001 & $-0,35$ & 0,11 & 9,98 & 0,002 & $-0,34$ & 0,11 & 9,44 & $-0,34$ \\
\hline$F_{7}$ & $-0,32$ & 0,11 & 8,13 & 0,004 & $-0,31$ & 0,11 & 7,53 & 0,006 & $-0,29$ & 0,11 & 6,72 & $-0,29$ \\
\hline$F_{8}$ & & & & & 0,46 & 0,12 & 14,73 & 0,000 & 0,45 & 0,12 & 14,28 & 0,45 \\
\hline$F_{9}$ & & & & & & & & & $-0,24$ & 0,12 & 4,24 & $-0,24$ \\
\hline$F_{10}$ & & & & & & & & & 0,09 & 0,14 & 0,44 & 0,09 \\
\hline
\end{tabular}

3.4.3.2. The Assessment of the Performance of the Model

The discriminatory power of the three previous $C P A$ models determined by the $A U C$ is presented as follows:

Table 22. The $A U C$ as a function of the model

\begin{tabular}{|c|c|c|c|}
\hline & Model 2 & Model 3 & Model 4 \\
\hline AUC & 78,4 & 79,8 & 80,2 \\
\hline
\end{tabular}

The three models have a discriminatory power that varies between acceptable and good. As a result, they can be used to classify companies and determine the probability of default.

\subsubsection{The Score Function per Level of Cumulative Variation}

The score function is defined per level of cumulative variation as follows:

\section{- $\quad$ The score function of the model 2}

$S_{1}=3,02+0,52 * F_{1}+0,04 * F_{2}-0,14 * F_{3}+0,01 * F_{4}+0,66 * F_{5}-0,37 * F_{6}-0,32 * F_{7}$

\section{- The score function of the model 3}

$S_{2}=3,08+0,53 * F_{1}+0,02 * F_{2}-0,14 * F_{3}+0,02 * F_{4}+0,65 * F_{5}-0,35 * F_{6}-0,31 * F_{7}+0,46 * F_{8}$

\section{- The score function of the model 4}

$$
\begin{array}{rl}
S_{3}=3,10+0,54 & * F_{1}+0,04 * F_{2}-0,13 * F_{3}+0,03 * F_{4}+0,64 * F_{5}-0,34 * F_{6}-0,29 * F_{7}+0,45 * F_{8}-0,24 \\
& * F_{9}+0,09 * F_{10}
\end{array}
$$

\subsubsection{Calculation of the Expected Credit Loss per Model}

\subsubsection{The Probability of Default per Rating Class and per Model}

The probability of default per rating class for the three models based of the CPA is represented as follows:

Table 2. The $P D$ per rating class for the three models based of the $C P A$

\begin{tabular}{|c|c|c|c|}
\hline \multirow{2}{*}{ Rating class } & \multicolumn{2}{|c|}{ PD per model } & Model 4 \\
\cline { 2 - 4 } & Model 2 & Model 3 & $0,03 \%$ \\
\hline A & $0,03 \%$ & $0,03 \%$ & $1,20 \%$ \\
\hline B & $1,15 \%$ & $1,19 \%$ & $3,50 \%$ \\
\hline C & $3,11 \%$ & $3,15 \%$ & $6,77 \%$ \\
\hline D & $6,45 \%$ & $6,54 \%$ & $8,61 \%$ \\
\hline F & $8,21 \%$ & $8,42 \%$ & $9,80 \%$ \\
\hline G & $10,53 \%$ & $11,00 \%$ & $22,92 \%$ \\
\hline
\end{tabular}

3.4.4.2. The Expected Credit Loss per Model

The expected credit loss per model is determined on the basis of the $E A D$ and the $P D$ per rating class. 
Table 24. The expected credit loss per model (Million MAD)

\begin{tabular}{|c|c|c|c|c|c|c|c|c|c|}
\hline & \multicolumn{3}{|c|}{ Model 2 } & \multicolumn{3}{c|}{ Model 3 } & \multicolumn{2}{c|}{ Model 4} \\
\hline rating & $E A D$ & $P D$ & $E L_{M}$ & $E A D$ & $P D$ & $E L_{M}$ & $E A D$ & $P D$ & $E L_{M}$ \\
\hline A & 51 & $0,03 \%$ & 0,00 & 53 & $0,03 \%$ & 0,01 & 50 & $0,03 \%$ & 0,00 \\
\hline B & 938 & $1,15 \%$ & 3,38 & 995 & $1,19 \%$ & 5,15 & 936 & $1,20 \%$ & 3,63 \\
\hline C & 1993 & $3,11 \%$ & 27,47 & 2086 & $3,15 \%$ & 29,57 & 1978 & $3,50 \%$ & 33,32 \\
\hline D & 2679 & $6,45 \%$ & 84,04 & 2546 & $6,54 \%$ & 71,89 & 2565 & $6,77 \%$ & 82,22 \\
\hline E & 1454 & $8,21 \%$ & 59,41 & 1293 & $8,42 \%$ & 58,79 & 1339 & $8,61 \%$ & 55,95 \\
\hline F & 702 & $10,53 \%$ & 27,68 & 668 & $11,00 \%$ & 34,18 & 665 & $9,80 \%$ & 27,85 \\
\hline G & 234 & $28,86 \%$ & 42,58 & 410 & $30,29 \%$ & 34,57 & 518 & $22,92 \%$ & 46,89 \\
\hline H & 489 & $72,05 \%$ & 156,74 & 489 & $81,40 \%$ & 179,27 & 489 & $74,50 \%$ & 172,32 \\
\hline Total & 8540 & & 401,30 & 8540 & & 413,43 & 8540 & 422,18 \\
\hline
\end{tabular}

\subsection{Comparison of Expected Credit Losses per Model.}

The comparison of the models, based on their performances, show that the models resulting from the principal components analysis, are more performing in terms of discriminatory power. Indeed:

Table 25. The comparison of the performance of the four models.

\begin{tabular}{|c|c|c|c|c|}
\hline Models & Model 1 & Model 2 & Model 3 & Model 4 \\
\hline AUC(\%) & 70,5 & 78,4 & 79,8 & 80,2 \\
\hline
\end{tabular}

For the expected credit loss, we noticed that it increases in parallel with the increase in cumulative variation to approach the expected credit loss determined by the pure logistic regression.

Table 26. The comparison of expected credit losses of the four models.

\begin{tabular}{|c|c|c|c|c|}
\hline Models & Model 1 & Model 2 & Model 3 & Model 4 \\
\hline$V C(\%)$ & 100 & 70 & 80 & 90 \\
\hline $\begin{array}{c}E L_{M}(\text { Million } \\
M A D)\end{array}$ & 425,69 & 393,59 & 401,69 & 413,03 \\
\hline Variation & $0 \%$ & $5,73 \%$ & $2,88 \%$ & $0,82 \%$ \\
\hline
\end{tabular}

\section{Conclusions}

Credit risk is the most important aspect of the banking risk management. Indeed, banks must continuously monitor the adequacy of their capital with the risks taken because they must cover the unexpected loss and must constitute a provision to cover expected losses.

The expected losses are deducted from the result, this, impact directly the level of core capital. Therefore, their calculation must be meticulous to avoid regulatory penalties on the one hand, and not to generate a lack to ganger for the bank on the other hand.

The rating system impact directly the calculation of expected losses because it provides the different components which are the probability of default $(P D)$, the loss given default $(L G D)$ and the exposure at default $(E A D)$ per rating class and per counterparty for the calculation of the loss amount. As a result, the expected loss amounts depend directly on the modelling approach used.

In this article, we have constructed four rating models that have an acceptable discriminatory power that allow them to predict counterparty default. Indeed, we constructed the first model by using the pure logistic regression approach and the other three models from the principal components on the basis of the cumulative variation, which must be superior to $70 \%$.

The passage from the initial variables to the principal components to model the failure can generate a loss of information, particularly in terms of correlation between the eigenvectors and the default.

The expected loss amounts calculated by the four models are different. We conclude that those determined from the logistic regression on the principal components, they increase in parallel with the increase in cumulative variation and are lower of the expected loss calculated by the pure logistic regression model.

This study shows that there is multitude of powerful models of failure prediction, which offer several structures of probability of default per rating class, enable to calculate of various expected loss amounts. As a result, the amount of expected losses becomes a random variable, depends of the model.

In our study, the uncertainty for the second model reaches the threshold of $5.73 \%$. Probably, it will be greater if one opts for other types of models, such as Bayesian modelling or genetic algorithms or fuzzy numbers. In this context, the research focusing on the modelling of the probability of default by the three previous logics can help to determine the degree of uncertainty.

For this reason, the regulator must standardize the used techniques for the construction of the internal models in order to reduce uncertainty and enable a comparison of the credit risk profiles of banks. Indeed, the regulator must provide a standard approach for calculating the expected loss similar to that provided for the unexpected loss (weighted assets) and requires, as a result, that the expected losses calculated by the internal models must not be below 
a fixed floor in relation to the standard measurement.

\section{REFERENCES}

[1] Alonzo, T.A. Pepe, M.S. (2002). Distribution-free ROC analysis using binary regression techniques. Biostatistics 3, 421-432.

[2] Altman E.I. (1968). Financial ratios, discriminant analysis and the prediction of corporate bankruptcy, Journal of Finance, 23(4), September, 589-609.

[3] Altman, E. (2006). Are historically based default and recovery models in the high-yield and distressed debt markets still relevant in today's credit environment, Stern School of Business, Special Report.

[4] Altman, E. (2010). Default recovery rates and LGD in credit risk modeling and practice. Working Paper, URL: http://people.stern.nyu.edu/ealtman/UpdatedReviewofLiter ature.pdf

[5] Altman, E., Kalotay, E. (2010). A flexible approach to modeling ultimate recoveries on defaulted loans and bonds. Working Paper, URL: http://pages.stern.nyu.edu/ ealtman/ FlexibleRecovery_v1.1.pdf

[6] [6] Altman, E., Brady, B., Resti, A., and Sironi, A. (2003). The link between default and recovery rates: theory, empirical evidence, implications.Working Paper S-CDM-04-07, Series Credit \& Debt Markets Research Group

[7] Altman, E., Resti, A., Sironi, A. (2004). Default recovery rates in credit risk modeling: A review of the literature, empirical evidence. Economic Notes 33, 183-208.

[8] Back B, Laitinen T, Sere K, Wezel M.V. (1996). Choosing bankruptcy predictors using discriminant analysis, Logit analysis and Genetic Algorithms. Turku Center for Computer Sience, Technical Report, 40, 1-18.

[9] Bade, B., Rösch, D., Scheule, H. (2011). Empirical performance of loss given default prediction models. The Journal of Risk Model Validation 5(2), 25-44.

[10] Bardos M. (1998). Detecting the risk of company failure at the Banque of France. Journal of Banking and Finance, 22, 1405-1419.

[11] Basel Committee on Banking Supervision, 2006, International Convergence of Capital Measurement and Capital Standards, Bank for International Settlements.

[12] Basel Committee on Banking Supervision, 2015. Guidance on credit risk and accounting for expected credit losses. Bank for International Settlements.

[13] Bell T. B., Ribar G. S., Verchio J. R. (1990). Neural Nets Vs. Logistic Regression: A Comparison of Each Model's Ability to Predict Commercial Bank Failures. Proceedings of the 1990 Deloitte and Touche-University ofKansas Symposium on Auditing Problems, 29-58.

[14] Bellotti, T., Crook, J. (2012). Loss given default models incorporating macroeconomic variables for credit cards. International Journal of Forecasting, Special Section 2:
Credit Risk Modelling and Forecasting 28(1), 171-182.

[15] Bijak, K. , Thomas, L. C. (2015). Modelling LGD for unsecured retail loans using Bayesian methods. Journal of the Operational Research Society, 66, 342-352.

[16] BOSE, I., PAL, R. (2006), Predicting the Survival or Failure of Click-and-Mortar Corporations: A Knowledge Discovery Approach, European Journal of Operational Research, vol. $174, n^{\circ} 2$, pp. 959-982.

[17] Brown, I. (2011). Regression model development for credit card exposure at default (EAD) using SAS/STAT ${ }^{\circledR}$ and SAS ®Enterprise Miner TM 5.3. Las Vegas, NV: SAS Global Forum

[18] Bunn P., Redwood V. (2003), Company account based modeling of business failures and the implications for financial stability , The Bank of England's Working Papers Series $N^{\circ} 210$

[19] Chalupka R.,Kopecsni J.(2009).Modeling bank loan LGD of corporate and SME segments: acasestudy. Czech Journal of Economics and Finance 59(4), 360-382.

[20] Das, S.R., Fan, R., Geng, G., 2002. Bayesian migration in credit ratings based on probabilities of default. Journal of Fixed Income 12, 17-23.

[21] Dwyer, D.W., 2006. The Distribution of Defaults and Bayesian Model Validation. Moody KMV.

[22] E.N.C.Tong,Christophe Mues,Iain Brown, Lyn C.Thomas,(2016), Exposure at default models with and without the credit conversion factor, European Journal of Operational Research 252, 910-920

[23] Friedman N., Geiger D., Goldszmidt M., (1997), Bayesian Network Classifiers, Machine Learning, vol. 29, no 2-3, 1997, p. 131-163.

[24] Gemela, J., 2001. Financial analysis using bayesian networks. Applied Stochastic Modelsin Business and Industry 17 (1), 57-67

[25] Gôssl, C., 2005. Predictions Based on Certain Uncertainties, A Bayesian Credit Portfolio Approach. Working Paper, Hypo Vereinsbank AG, London.

[26] Grover J., Lavin A. (2001), Financial Ratios, Discriminant Analysis and the Prediction of Corporate Bankruptcy: A Service Industry Extension of Altman's ZScore Model of Bankruptcy Prediction, Southern Finance Association Annual Meeting, November, 2001.

[27] Gurtler, M., Hibbeln, M. (2011). Pitfalls in modeling loss given default of bank loans. Working Paper, Technische Universität Braunschweig.

[28] Hensher, D A., Jones S., William H. Greene W H. (2007), An Error Component Logit Analysis of Corporate Bankruptcy and Insolvency Risk in Australia, The Economic Record, 83, 86-103.

[29] Hosmer D., Lemeshow S., Sturdivant R. (2013). Applied Logistic Regression, 3rd Ed., John Wiley \& Sons, New York.

[30] Huang, X., Oosterlee, C.W. (2012). Generalized beta regression models for random loss given default. The Journal of Credit Risk 7(4), 45-70. 
[31] Hunter J., Isachenkova N. (2002), A panel analysis of UK industrial company failure, ESRC Centre for Business Research Working Paper 228, Cambridge University.

[32] Liang L., Wu D. (2003). An application of pattern recognition on scoring Chinese corporations financial conditions based on back propagation neural network. Computers et Operations Research, 32, 1115-112

[33] McDonald, J. F., Moffitt, R. A. (1980).The uses of Tobit analysis. Review of Economics and Statistics 62(2), 318321.

[34] Ohlson J. A. (1980). Financial Ratios and the Probabilistic Prediction of Bankruptcy. Journal of Accounting Research, 18-1,109-131.

[35] Oreski, S., Oreski, D., Oreski, G, (2012). Hybrid system with genetic algorithm and artificial neural networks and its application to retail credit risk assessment. Expert Systems with Applications, 39, 12605-12617.

[36] Pereira, T. L., Cribari-Neto, F. (2010). A test for correct model specification in inflated beta regressions. Working Paper, Instituto de Matemática, Estatística e Computação Científica Universidade Estadual de Campinas. URL: http://www2.ime.unicamp.br/sinape/sites/default/files/reset _beoi.pdf

[37] Sigrist, F., Stahel, W. A. (2011). Using the censored gamma distribution for modeling fractional response variables with an application to loss given default. ASTIN Bulletin 41(2), 673-710.

[38] Sigrist, F., Stahel,W. A. (2010). Censored gamma regression models for limited dependent variables with an application to loss given default. In 28th European Meeting of Statisticians, August 17-22, 2010, Piraeus, Greece.

[39] Taffler R.J. (1982), Forecasting company failure in the UK using discriminant analysis and financial ratio data, Journal of the Royal StatisticalSociety, Series A, General, 145(3), 342-358

[40] Taplin, R., Minh To, H., \& Hee, J. (2007). Modeling exposure at default, credit conversion factors and the Basel II accord. The Journal of Credit Risk, 3 , 75-84 .

[41] Tasche D. (2013). Bayesian estimation of probabilities of default for low default portfolios. Journal of Risk Management in Financial Institutions, Vol. 6, Iss. 3, 302-326

[42] Yang, B. H. , \& Tkachenko, M. (2012). Modeling exposure at default and loss given default: Empirical approaches and technical implementation. The Journal of Credit Risk, 8, 81102.

[43] Zmijeriski M. (1984). Methodological issues related to the estimation of financial distress prediction models. Journal of Accounting Research, 22, 59-82.

[44] Bewick, V., Cheek, L. and Ball,L.(2004). Receiver operating characteristic curves. Critical Care December 2004 Vol 8 No 6,508-512.

\footnotetext{
i Jel Classification: C12, C13, C51, G21, G32
} 